\title{
Wood pellet milling tests in a suspension-fired power plant
}

Masche, Marvin; Puig-Arnavat, Maria; Wadenbäck, Johan ; Clausen, Sønnik; Jensen, Peter A.; Ahrenfeldt, Jesper; Henriksen, Ulrik B.

\section{Published in:}

Fuel Processing Technology

Link to article, DOI:

10.1016/j.fuproc.2018.01.009

Publication date:

2018

Document Version

Peer reviewed version

Link back to DTU Orbit

Citation (APA):

Masche, M., Puig-Arnavat, M., Wadenbäck, J., Clausen, S., Jensen, P. A., Ahrenfeldt, J., \& Henriksen, U. B. (2018). Wood pellet milling tests in a suspension-fired power plant. Fuel Processing Technology, 173, 89-102. https://doi.org/10.1016/j.fuproc.2018.01.009

\section{General rights}

Copyright and moral rights for the publications made accessible in the public portal are retained by the authors and/or other copyright owners and it is a condition of accessing publications that users recognise and abide by the legal requirements associated with these rights.

- Users may download and print one copy of any publication from the public portal for the purpose of private study or research.

- You may not further distribute the material or use it for any profit-making activity or commercial gain

- You may freely distribute the URL identifying the publication in the public portal

If you believe that this document breaches copyright please contact us providing details, and we will remove access to the work immediately and investigate your claim 


\title{
Wood pellet milling tests in a suspension-fired power plant
}

Marvin Masche ${ }^{a *}$, Maria Puig-Arnavat ${ }^{a}$, Johan Wadenbäck ${ }^{b}$, Sønnik Clausen ${ }^{a}$, Peter A. Jensen $^{a}$, Jesper Ahrenfeldt ${ }^{a}$, Ulrik B. Henriksen $^{a}$

${ }^{a}$ Department of Chemical and Biochemical Engineering, Technical University of Denmark, 2800 Kgs. Lyngby, Denmark

${ }^{b}$ Amagerværket, HOFOR A/S, Kraftværksvej 37, 2300 Copenhagen S, Denmark

* Corresponding author. E-mail address: $\underline{\text { marv@kt.dtu.dk (M. Masche) }}$

\begin{abstract}
This paper investigates the milling behavior of two industrial wood pellet qualities (designated I1 and I2 as per ISO 17225-2:2014) in large-scale coal roller mills, each equipped with a dynamic classifier. The purpose of the study was to test if pellet comminution and subsequent particle classification (i.e., the classifier cut size) are affected by the internal pellet particle size distribution obtained after pellet disintegration in hot water. Furthermore, optimal conditions for comminuting pellets were identified. The milling behavior was assessed by determining the specific grinding energy consumption and the differential mill pressure. The size and shape of comminuted pellets sampled from burner pipes were analyzed by dynamic image analysis and sieve analysis, respectively. The results showed that the internal pellet particle size distribution affected both the milling behavior and the classifier cut size. I2 pellets with coarser internal particles than I1 pellets required more energy for milling, led to a higher mill pressure drop and showed a larger classifier cut size. Comminuted pellet particles sampled from burner pipes were notably
\end{abstract}


finer than internal pellet (feed) particles. At similar mill-classifier conditions, characteristic particle sizes of $0.50 \mathrm{~mm}$ for comminuted I1 pellets (compared to $0.83 \mathrm{~mm}$ for material within I1 pellets) and of $0.56 \mathrm{~mm}$ for comminuted I2 pellets (compared to $1.09 \mathrm{~mm}$ for material within 12 pellets), respectively, were obtained. Pellet comminution at lower mill loads and lower primary airflow rates reduced the mill power consumption, the mill pressure drop, and the classifier cut size. However, this was at the expense of a higher specific grinding energy consumption. Derived 2D shape parameters for comminuted and internal pellet particles were similar. Mill operating changes had a negligible effect on the original elongated wood particle shape. To achieve the desired comminuted product fineness (i.e., the classifier cut size) with lower specific grinding energy consumption, power plant operators need to choose pellets with a finer internal particle size distribution.

\section{Keywords}

Wood pellets; Roller mills; Specific grinding energy consumption; Particle size; Particle shape

\section{Introduction}

Wood pellets as a renewable energy commodity for heat and power generation have experienced tremendous growth over the past decade in Europe [1,2]. European energy policies have driven this development to mitigate greenhouse gas emissions by $20 \%$ by 2020 [3]. In particular, USA, Canada, and Russia have responded to the increasing demand for wood pellets by enhancing pellet production, with many large-scale pellet plants being constructed for the European market [4]. When tons of solid biomass need to be transported overseas, pelletized biomass is more cost-efficient than wood chips because of higher 
energy and bulk density [5]. Furthermore, pelletization improves storage and handling characteristics with fewer dust emissions [6] that may increase the risk of explosions during transshipment [7]. To mitigate industrial greenhouse gas emissions, retrofitting power plants from coal to wood pellets by utilizing the existing milling equipment and auxiliary infrastructure offers a cost-efficient and practical option at low capital investment [8]. Furthermore, the converted plants preserve grid reliability compared to intermittent renewable energies like wind and solar [9]. Countries, like Denmark and United Kingdom, have already converted, or are currently converting their existing suspension-fired power plants from coal to operate $100 \%$ on biomass, mostly wood pellets [8].

The size reduction of solid particles is a significant process in suspension-fired power plants and is commonly performed in hammer mills or roller mills $[8,10]$ to achieve a homogenous fuel distribution that is pneumatically transported to the burners. Previous studies [11-13] showed that roller mills were not capable of producing a product as fine as hammer mills. Regarding the particle shape, Trubetskaya et al. [12] found no difference between roller-milled and hammer-milled particles. However, roller mills required less power for grinding than hammer mills $[12,13]$. The energy needed for milling biomass depends on the feed moisture, particle size reduction ratio, feedstock characteristics [14], feed rate and mill operating parameters [15]. Comminuting fibrous and orthotropic elastic wood that is capable of absorbing energy before size reduction [16] requires more energy than coal regardless of mill type [17].

The comminuted particle size and shape are essential properties for suspension-firing, as they influence the particle dynamics, particle heat and mass transfer [18]. For proper 
combustion control, the finer and more uniform the fuel is, the higher the chance to achieve complete combustion in the available boiler residence time [19]. To provide control over the fineness (i.e., the cut size) of the comminuted product conveyed to the burners, coal roller mills apply static or dynamic classifiers [8,20], which classify particles based on their shape, size, and density [21]. The cut size is based on Stokes' law [22] that is only valid for the drag force of a spherical particle [23]. Williams et al. [17] found that the classification system of a ring-roller mill for the comminution of densified biomasses followed the Stokes' law, indicated by an increasing sphericity with decreasing particle size. In largescale mill classifiers, there are particle size limits for coal suspension-firing. In particular, $75 \%$ of pulverized coal needs to pass a 200 mesh sieve $(75 \mu \mathrm{m})$ [24]. Equivalent limits for woody biomass particles have not been established. However, a size reduction to the same level as coal may not be required due to the higher volatile content of biomasses in combustion systems [19]. Esteban and Carrasco [10] recommend $95 \%$ of wood particles (dry weight basis) to be below $1 \mathrm{~mm}$ for optimal combustion. Adams et al. [25] found that $25 \%$ of biomass (dry weight basis) below $100 \mu \mathrm{m}$ was ideal for excellent flame stability.

The study aims to assess the large-scale milling behavior of industrial wood pellet qualities in vertical roller mills (VRMs) at the suspension-fired combined heat and power (CHP) plant Amagerværket unit 1 (AMV1), located in Copenhagen (Denmark). AMV1 has a capacity of $80 \mathrm{MW}$ electricity and $250 \mathrm{MW}$ heat. Originally designed for coal, AMV1 was converted in 2010 to operate $100 \%$ on biomass, mainly wood pellets. The purpose of the study is to test if large-scale pellet comminution in VRMs and subsequent particle separation in dynamic classifiers are affected by the particle size distribution (PSD) of 
material within pellets, also known as the internal pellet PSD. To the best knowledge of the authors, this is the first study that compares the large-scale milling behavior of industrial wood pellet qualities. The results provided can be valuable to optimize the overall milling and combustion process for plant operators facing the problems of changing from coal to biomass pellets. Thus, the main objectives of the study are:

- To evaluate the sampling method for comminuted pellets conveyed to the burners.

- To compare the morphology (size and shape) of material within pellets with that from pellets comminuted at different mill loads.

- To analyze the influence of different pellet qualities on the milling process.

- To identify optimal conditions for comminuting wood pellets.

\section{Materials and methods}

\subsection{Materials}

Two industrial wood pellet qualities characterized in triplicate according to standardized methods were used (Table 1). The first quality fully conformed to the requirements of industrial pellets of class I1 according to ISO 17225-2:2014 [26] and was hence designated as I1. They were mainly softwood pellets made from Norway spruce (Picea abies) and Scots pine (Pinus sylvestris). They were produced in the Baltic countries. The second pellet quality met the specifications set out for industrial pellets of class I2 [26] and was hence

designated as I2. They originated from the Southeastern United States and were made of ca. $93 \%$ softwood, mainly Southern yellow pine wood species, such as loblolly pine (Pinus taeda), and $7 \%$ mixed hardwood species. The major difference between both pellet 
qualities was the internal PSD, which was obtained after pellets have been disintegrated in hot deionized water and dried in an oven [27]. Sieve analysis was then performed to determine the internal PSD of the dried material. The internal PSD of I1 pellets featured a $20 \%$ higher mass fraction of particles below $1 \mathrm{~mm}$ compared to 12 pellets.

\subsection{Vertical roller mills and dynamic classifiers}

Pellets were comminuted in three coal VRMs (type LM 19.2 D, Loesche GmbH, Germany), each equipped with a dynamic (or rotary) classifier (type LSKS 27 ZD-4 So, Loesche GmbH, Germany). The mills were denoted as M10 (mill 10), M20 (mill 20) and M30 (mill 30). The mills, i.e., the milling table, were driven by an electric motor via a vertical gearbox. A schematic representation of the design features of a Loesche coal VRM is shown in Fig. 1. The technical specifications for the mills are summarized in Table 2. The throughput rate for wood pellets is reduced due to their lower energy density compared to coal [8].

The pellet milling process comprises comminution, drying, particle classification and product discharge to the burners. As shown in Fig. 1, pellets fall from the side into the center of the rotating milling table, which is equipped with a dam ring for the adjustment of the milling bed thickness. Centrifugal forces move the pellets under two tapered, locally fixed, grinding rollers that are mounted in rocker arms. Compression force originating from the hydraulic-pneumatic, spring-loaded roller system comminutes the pellets. The rollers also achieve a sliding movement that results in additional shearing forces to comminute the pellets. To produce higher shearing forces, the existing roller mills at AMV1 were retrofitted. Holes were drilled into the roller track, and a surface material with higher 
hardness was applied to the roller surface. The rollers are driven by the grinding material and are moving vertically during the comminution process. As the rollers roll over the milling bed, the rocker arms, which are coupled to the pistons of the two linked hydraulic cylinders, start to move. Centrifugal forces again expel the comminuted pellet material over the rim of the milling table into the vicinity of the surrounding louvre ring. The louvre ring directs a hot primary airflow, which is tempered by a cooler to around $130^{\circ} \mathrm{C}$ to avoid pellet pre-ignition and mill fires, upwards into the spinning rotor of the dynamic classifier. By this means, the comminuted pellet material is dried and lifted to the classifier [28]. The internal flow path of material from the milling table to the classifier is shown in Fig. 1.

In the classifier, drag or centripetal forces (generated by the airflow to the rotor), and mass or centrifugal forces (generated by the rotor rotation) act upon the particles [20]. If the mass force is greater than the drag force, coarse particles are rejected by the classifier and fall back to the milling table via the grit cone for further size reduction. Else, if the drag force is greater than the mass force, the primary airflow lifts the fine particles upwards in the classifier housing [29]. The balance between both forces governs the particle separation [24]. If both forces are in equilibrium for a specific particle mass, the rotor classifies the particle with $50 \%$ efficiency, which is referred to as the classifier cut size. Plant operators can control the cut size, and thus the degree of product fineness by adjusting the classifier rotor speed, dam ring height, milling table speed, airflow rate $\left(\dot{m}_{\text {Air }}\right)$, hydraulic grinding pressure $(H G P)$ of the roller, and pellet feed rate $\left(\dot{m}_{\text {Pellet }}\right)[20,30,31]$. The fines eventually leave the mill at a mill outlet temperature of $60^{\circ} \mathrm{C}$ via four outlet pipes to four burners. In total, AMV1 has 12 
front-wall-fired burners, each fed by a separate burner pipe distributed in three different levels, one for each mill (Fig. 2).

\subsection{Sampling equipment}

Wood pellets were sampled from the end of a continuously moving conveyor belt before entering the mill using a falling stream sampler. According to ISO 14488:2007 [32], isoaxial and isokinetic sampling with cyclone was used as a sampling probe to extract the fine comminuted pellet product via a vacuum with a mean air velocity of $30 \mathrm{~m} / \mathrm{s}$ from inside the burner pipes. The air velocity was measured by an airflow meter in the wood dust-laden environment. The samples were extracted from the burner pipe center, as it shows a more stable particle flow than along the pipe wall [33]. Dustless connectors were installed at the sampling ports to eliminate any wood dust leakage while inserting and removing the sampling device. The sampling ports for wood dust leaving M10 were placed in horizontal sections of the pipes, while those ports exiting M20 and M30 are located in vertical sections of the pipe (Fig. 2). The mill-burner configuration shows that the outlet pipes exiting M20 were configured nearly symmetrically. The pipe length was approximately equal from mill outlet to burners B22 and B23 and from mill outlet to burners B21 and B24, respectively. However, this was not the case for pipes exiting M10 and M30. For subsequent particle shape and size analysis, collected wood dust samples were split into representative subsamples by a rotating sample divider (type PT100, Retsch Technology GmbH, Germany). 


\subsection{Milling tests}

Table 3 shows the conditions for different roller milling scenarios during steady-state operation. Average values for the operating conditions were recorded in the central control room at AMV1. The measured range of mill operating parameters and the sensor types used are summarized in Table 4. In total, the following 12 milling scenarios were chosen:

- Scenario 1: test the precision of sampling comminuted pellets conveyed to the burners,

- Scenario 2: compare the comminuted pellet PSD obtained by sieving and Camsizer X2,

- Scenarios 2-4: compare sampling from vertical and horizontal mill outlet pipes,

- Scenarios 5-6: compare the size and shape of disintegrated I1 and I2 pellets versus I1 and $\mathrm{I} 2$ pellets comminuted at similar steady-state milling conditions,

- Scenarios 6-7: test the influence of airflow rate and classifier rotor speed changes,

- Scenarios 7-12: test the influence of mill load changes when milling I1 and I2 pellets.

\subsection{Pellet milling behavior}

The specific grinding energy consumption $(S G E C)$ was used as a measure of the total energy consumed during the grinding process, and expressed by the following equation:

SGEC $=\int_{0}^{t} \frac{P}{m_{\text {Pellets }}} d t$

Where $m_{\text {Pellets }}$ was the amount of wood pellets ( $\mathrm{t}$ ) measured by continuous weighing the conveyor belt to the mill. $P$ was the total, instantaneous power $(\mathrm{kW})$ consumed while comminuting at time $t(\mathrm{~h})$, which was obtained from a data logger. $P$ was assumed to go directly into the grinding process as the mill table is rotated. $S G E C$ was hence a result of 
the pellet feed rate and the grindability of the pellets under given operating conditions. However, $S G E C$ is only an estimate of the actual motor energy required for grinding, as the idle power without pellets has to be deducted from the total power consumption, and as some amount is dissipated as thermal energy. Thus, the energy transferred to comminute pellets specifically is not provided. The differential pressure $(\Delta p)$ across the mill was used as a measure of the instantaneous mill load due to the level of material being ground and material circulating within the mill. It represented the static differential pressure measured at the mill inlet and outlet (Fig. 1). A low drop in pressure is desirable, but factors such as $\dot{m}_{\text {Pellets }}, \dot{m}_{\text {Air }}$, and mill geometry lead to an increased $\Delta p[34]$.

\subsection{Fine comminuted pellet size and shape characterization}

\subsubsection{Sieve analysis}

A vibratory sieve shaker (type AS 200 control, Retsch Technology GmbH, Germany) determined the comminuted pellet PSD. The stack comprised seven square-hole sieves each with a diameter of $200 \mathrm{~mm}$, and aperture sizes of $0.09,0.25,0.50,1.00,1.40,2.00$ and $2.80 \mathrm{~mm}$, mounted on a collecting pan. About $50 \mathrm{~g}$ of comminuted pellets were tested. An electronic balance (type EW-N, KERN \& SOHN GmbH, Germany) weighed the individual sieves and pan before and after sieving. This information was converted into a cumulative (undersize) weight distribution, representing the percentage of sample passing through each sieve. Sieve analysis was run for $10 \mathrm{~min}$ with $1 \mathrm{~mm}$ amplitude and performed in duplicate.

\subsubsection{Dynamic image analysis}

A dynamic image analyzer (type Camsizer ${ }^{\circledR} \mathrm{X} 2$, Retsch Technology GmbH, Germany) recorded the size and shape of comminuted pellets using two linked cameras (basic and 
zoom camera) with a resolution of 4.2 megapixels per image, covering a measuring range from $30 \mu \mathrm{m}$ to $8 \mathrm{~mm}$. The particles are individually detected as projected areas, digitalized and the images processed. The X-Jet mode of the Camsizer ${ }^{\circledR} \mathrm{X} 2$ was used to disperse the agglomerated wood dust falling from a vibrating feeder by a compressed air-driven venturi nozzle. Preliminary tests were run to estimate the optimal compressed air pressure $(30 \mathrm{kPa})$ and sample size (15-20 g). The measurements were done in triplicate.

Compared to sieve analysis, the PSD from Camsizer $^{\circledR} \mathrm{X} 2$ is presented as a cumulative (undersize) volume distribution versus $x_{c, \min .} x_{c, \min }$ stands for the shortest maximum chord of a 2D particle projection measured from all measurement directions, and thus represents the width of a particle projection. Preliminary tests and a previous study [17] show that this parameter gives the closest results to those obtained by sieve analysis. Camsizer $^{\circledR} \mathrm{X} 2$ software also provides the aspect ratio (width-to-length ratio) and circularity values among other 2D shape factors. The Camsizer ${ }^{\circledR}$ definition of the circularity is the ISO 9276-6:2008 standard definition squared [35]. Both shape factors are commonly used for describing comminuted wood particle shapes $[12,17]$. The aspect ratio $(A R)$ ranging between zero and one is defined as follows:

$A R=\frac{x_{c, \min }}{F e_{\max }}$

Where $F e_{\max }$ is the maximum Feret diameter (longest distance between two parallel tangents of the particle at any arbitrary angle) or maximum caliper diameter. Trubetskaya et al. [36] showed that $F e_{\max }$ is suitable to represent the length of particles. The circularity $(C)$, which is also a measure of the particle roundness [37], indicates how closely the particle resembles a circle: 
$C=\frac{4 \cdot \pi \cdot A_{\text {particle }}}{P_{\text {particle }}^{2}}$

Where $A_{\text {Particle }}$ and $P_{\text {Particle }}$ refer to the particle projection area and the particle perimeter, respectively. A value of one corresponds to a perfect circle.

\subsubsection{Data analysis}

The Rosin-Rammler-Bennet-Sperling (RRBS) model describes the comminuted product PSD. It is a two-parameter distribution function expressed as a cumulative percent (undersize) distribution. Previous studies [38-40] showed good correlation between RRBS fit parameters and measured milled particle sizes. The RRBS equation is [41]:

$R(d)=100-100 \cdot e^{-\left(\frac{d}{d^{*}}\right)^{n}}$

where $R(d)$ is the cumulative percent (undersize) distribution of material finer than the particle size $d, d^{*}$ is the characteristic particle size defined as the size at which $63,21 \%$ of the PSD lies below, and $n$ is the distribution parameter. A plot of $\ln [\ln [100 /(100-R(d)]]$ against $\ln (\mathrm{d})$ on the double logarithmic scale gives a straight line of slope $n$. The smaller the $n$-value, the wider the product PSD, whereas higher $n$-values imply a more uniform product distribution [42].

The 90th percentile $(D 90)$ of the cumulative undersize distribution was used to show the effect of operating conditions of the mill-classifier system on the comminuted product fineness. Yu et al. [43] found a very strong positive correlation between classifier cut size and product fineness $(D 90)$, as well as between cut size and fine product yield. A smaller cut size led to a finer dust collected and a smaller fine product yield. 
Von Rittinger's comminution law was used to analyze the relationship between SGEC and particle size reduction obtained by the mill-classifier system [44]:

$S G E C=K_{R}\left(\frac{1}{d_{p}}-\frac{1}{d_{f}}\right)$

where $d_{p}$ is the 90th percentile passing size of the comminuted product and $d_{f}$ is the 90th percentile passing size of the material within the pellet feed. The material characteristic parameter $K_{R}\left(\mathrm{kWh} \mathrm{mm} \mathrm{t}^{-1}\right)$ allows to characterize the pellet grindability by a single value. Recent studies $[14,17,45]$ suggest the applicability of Von Rittinger's law to predict the energy consumption during milling of biomass pellets.

\subsection{Statistical analysis}

Statistical analyses were performed using R Studio (version 1.0.143, R Studio Inc., Boston, USA). Pearson's correlation coefficients (r) were calculated to study the strength of the linear relationship between two parameters. Multiple comparisons using one-way analysis of variance (ANOVA) followed by a Tukey's HSD test for post-hoc analysis were conducted to determine if there were significant differences between the means of independent groups. All results were considered statistically significant at the $95 \%$ confidence level $(\mathrm{p}<0.05)$.

\section{Results and discussion}

\subsection{Precision testing of isokinetic sampling equipment}

Table 5 shows the flow characteristics of comminuted wood particles inside the vertical pipes exiting M30. It is clear that the distribution of comminuted wood particles and their characteristics are different among all four pneumatic pipes. Mill outlet pipes 2 and 3 nearly provide similar RRBS fit parameters and sample mass flows. The statistical analysis shows there is no statistically significant difference between pipe 2 and 3 regarding the 
uniformity constant ( $n$-value). Pipe 1 yields the finest and lowest wood dust sample flow, while pipe 4 provides the coarsest and largest wood dust sample flow. Thus, the larger fraction of coarse particles in pipe 4 makes up the bulk of the weight of the sampled wood dust, whereas the higher fraction of finer particles in pipe 1 may be the reason for the lower mass flow.

Differences among burner pipes can be attributed to an inappropriate distribution of mass of wood dust from the classifier to each of the pipes, to different air velocities in the pipe, and to the pipe geometry. The mill-burner configuration in Fig. 2 shows that M30 outlet pipes have no equal distances from the classifier to the burners. A longer pipe will result in a pressure drop due to static and dynamic effects in the pipe, causing a reduction of the flow of suspended wood dust particles. As pipe 1 is much longer than pipe 4, the pressure drop is more significant indicated by a four times lower sample mass flow. The reduced mass flow also leads to a lower velocity in the pipe, which will affect dust sampling [46]. Considering a similar sampling velocity for all pipes, the reduced pipe velocity in pipe 1 will cause a finer dust sample compared to pipe 4 indicated by lower $d^{*}$ and $D 90$ values. Differences in flow characteristics were also observed for M10 outlet pipes. Sampling from M20 outlet pipes showed similar flow characteristics that were attributed to their symmetric configuration. As a result, the focus of the present study was on M20. Relatively low confidence intervals in Table 5 indicate that isokinetic sampling and sieve analysis are precise and reliable methods.

Characterizing the flow properties of comminuted biomass particles inside a pneumatic pipe is more complex than for coal, due to their wider range of particle sizes and non- 
spherical particle shape $[33,47]$. Compared to coal, the flowability and flow stability of biomass particles are worse, increasing the risk of arching and blockage during the pneumatic conveying process [48]. The fine comminuted product was extracted isokinetically so that the suction velocity at the probe tip was equal to the mean conveying airflow velocity in the pipe. Qian and Yan [47], however, found that pneumatically conveyed biomass and flour, which was used to simulate pulverized coal, traveled slower in horizontal pipes than the conveying air due to their different size and shape. The slip velocity between the particles and the conveying air was lower for flour particles. Assuming a similar behavior for comminuted wood in the upward vertical pipes, as it was not possible to measure their mass flow and velocity, undersampling may have occurred. Due to the higher sampling velocity, the inertia of coarser particles will keep them from following the streamlines that converge into the sampling probe, and a finer sample will be obtained [46]. Under these conditions, there is a risk of underestimating the actual wood particle sizes. The slip velocity between the wood particles and the conveying air will require further quantitative investigation.

\subsection{Wood particle size determination by sieve analysis and Camsizer ${ }^{\circledR} X 2$}

Fig. 3 shows the PSD of comminuted I1 pellets analyzed by mechanical sieving and Camsizer ${ }^{\circledR} \mathrm{X} 2$ operated in the X-Jet mode. It shows very good agreement for particles larger or equal $0.5 \mathrm{~mm}$. That supports the observation of Gil et al. [40] that sieving data mainly describe the width of particles, especially for the large size fractions. However, sieving seems to underestimate the fraction retained on the $0.25 \mathrm{~mm}$ and $0.09 \mathrm{~mm}$ sieves. That could be explained by an increased dust cohesiveness when decreasing the particle 
size [49]. Particles below $0.5 \mathrm{~mm}$ become more sticky and cohesive and hence increase the tendency to block the sieve openings by forming agglomerates. These agglomerates remain on the sieve and thus diminish the mass of comminuted wood pellets in the finer fraction. The attractive forces (or agglomeration strength) between small particles mainly stem from van der Waals interactions [50]. Jensen et al. [51] showed that the accuracy of particle size analysis by sieving was reduced with decreasing particle size. The authors assumed that this was due to the increased tendency of particles clogging the openings of sieves with small mesh sizes. Rezaei et al. [52] ascribed the underestimation of the width of milled wood pellet particles by sieve analysis by its fractionation mechanism and particle interactions.

Derived 2D shape factors analyzed by Camsizer ${ }^{\circledR} \mathrm{X} 2$ indicated that the average circularity for comminuted particles increased for smaller particles. Thus, fines (i.e., particles below $0.5 \mathrm{~mm}$ ) with $C=0.54$ were more circular (i.e., rounder) than the coarse fraction (i.e., particles above $1.0 \mathrm{~mm}$ ) with $C=0.50$. Compared to coal particles that are nearly spherical [11], comminuted wood particles are very elongated due to the anisotropic wood structure [53], indicated by average particle aspect ratios of about $A R=0.53$. The study of the impact of the circular and elongated particle shape on inter-particle interactions would be a valuable contribution to the understanding of possible particle agglomerations on sieves with small apertures.

The RRBS model fits well the size distribution of comminuted pellets analyzed by both sieving $\left(R^{2}>0.998\right)$ and Camsizer ${ }^{\circledR} X 2\left(R^{2}>0.988\right)$, with sieving achieving a slightly better fit. Small error bars in PSD data in Fig. 3 indicate that we expect to get similar results from repeated measurements with high precision (i.e., reliability). Sieving does not provide 
information about the particle shape and is less accurate to describe the product fineness. Thus, the Camsizer ${ }^{\circledR} \mathrm{X} 2$ was used for the other milling scenarios to assess the size and shape of comminuted wood dust particles simultaneously.

\subsection{Comparison between horizontal and vertical pipe sampling}

The PSD of wood dust sampled from burner pipes exiting all three mills at AMV1 is shown in Fig. 4. The mill-burner configuration is shown in Fig. 2. Sampling distributions from M10 show an excess of fine particles, whereas PSDs from M20 and M30 are shifted towards coarser particle sizes. Differences can be attributed to the pipe orientation where the sampling point is mounted. Dust sampling from horizontal pipes may lead to particle segregation, where coarser particles move at the bottom level and fine particles are in suspension. Other studies $[33,54]$ also confirmed the effect of particle segregation in horizontal pipe sections. Samples from horizontal pipes are thus less representative. In contrast, the vertical M20 pipe network is more representative due to its symmetry. It is

more likely to achieve a uniform particle concentration in these pipes. The lowest error bars for the average PSD from M20 pipes compared to the PSDs from M10 and M30 pipes support this statement.

\section{4. $\quad$ Milling behavior of II and I2 pellets}

The PSDs of disintegrated I1 and I2 pellets compared with comminuted I1 and I2 pellets sampled from M20 burner pipes are shown in Fig. 5. Although the internal PSD of I2 pellets showed about $20 \%$ coarser particles below $1 \mathrm{~mm}$ compared to I1 pellets, the mill classifier nearly discharges a similar comminuted product to the burners. The statistical analysis showed no statistically significant difference in $n$ and $d^{*}$ between comminuted I1 
and $\mathrm{I} 2$ pellets. Table 6 shows that compared to the pellet feed material (i.e., disintegrated pellets), the $d^{*}$ and $D 90$ values significantly decrease by $40 \%$ and $19 \%$ for I1 pellets, respectively, and by $49 \%$ and $24 \%$ for I 2 pellets, respectively. It shows that the mill classifier limits coarser wood particles sent to the burners. However, isokinetic dust sampling may under-represent the amount of coarse particles, as mentioned in section 3.1.

The mill classifier, however, did not achieve the same comminuted product fineness (i.e., classifier cut size) indicated by statistically different $(\mathrm{p}<0.05)$ D90 values of comminuted I1 and 2 pellets (Table 6). Differences in the product fineness may be explained by wood pellet characteristics, such as internal pellet PSD and wood properties. In particular, the different anatomical structure of softwood and hardwood species may cause a different grinding behavior in the mill. The isokinetic sampling method could also explain these differences. Archary et al. [55] found that sampling coal at the center of vertically oriented burner pipes resulted in a higher concentration of coarse comminuted particles, while the fine particle fraction moved near the pipe wall. Hence, a coarser PSD of the comminuted I2 pellets may lead to an even higher concentration of coarser particles at the inner part of the pipe that is collected by the isokinetic sampling device. Error bars in Fig. 5 are larger for comminuted I 2 pellets than for I1 pellets, indicating a greater level of variation of the wood dust PSD in the burner pipes. The coarser comminuted I2 pellets, hence, seem to produce more unstable particle flow characteristics compared to the finer comminuted I1 pellets. This result is in accordance with recent work [33]. Thus, it might be more difficult to maintain a stable combustion when using I 2 pellets. Fig. 5 shows that about $76 \%$ of 
comminuted I 2 pellets are below $1 \mathrm{~mm}$ compared to $84 \%$ of comminuted I1 pellets. Hence, it will be more likely to achieve complete combustion of comminuted I1 pellets [10].

I2 pellets required a $45 \%$ higher power consumption for milling, a $45 \%$ higher $S G E C$ and led to a $29 \%$ higher $\Delta p$ compared to I1 pellets (Table 6). The higher $\Delta p$ may result from a higher accumulation of pellet material on the milling bed due to a larger quantity of coarse particles rejected by the classifier. Parameters such as moisture content, feed size, and mill operating conditions $[14,15]$ are known to influence the energy required for milling. The small difference in the durability of I1 and I2 pellets (Table 1) does probably not explain the different $S G E C$, as noted by Temmerman et al. [14]. They further stated that the higher the moisture content in wood pellets, the more energy was required during hammer milling. In the present study, however, comminuting moister I1 pellets showed a lower energy consumption. The hot airflow entering the mill may facilitate fast drying of the material to be milled. As shown by Williams et al. [45], dry comminution led to more consistent grinding energies across biomasses. Thus, the higher energy consumption required for comminuting I2 pellets compared to I1 pellets may be mainly due to the larger difference in PSD between the material within the pellet feed and the fine comminuted pellet product. This is in agreement with the Von Rittinger's comminution law [14]. The effect of pellets made from different wood species on the mill power consumption and the comminuted product fineness remains unclear and requires further investigation.

Fig. 6 shows derived 2D shape factors (aspect ratio and circularity) of comminuted and disintegrated pellets. The values for coarsest particles were neglected due to the small number of particles analyzed, leading to bad statistics. Overall, average circularity and 
aspect ratio distributions of disintegrated and comminuted pellets show similar trends regardless the differences in internal pellet PSD. That indicates that the effect of roller mills on the particle shape is negligible. The observed particle shape may be therefore related to the raw material size reduction step before pelletization that is commonly performed in hammer mills. Pichler et al. [38] obtained similar aspect ratios for dry spruce sawdust particles comminuted in a hammer mill. Our experimental results corroborate previous findings from Trubetskaya et al. [12] and Williams et al. [17] who found that comminuting pellets in lab-scale and large-scale roller mills only had little effect on the particle shape. Regarding circularity, the average values increase from 0.45 for the coarsest particles to about 0.57 for the finest particles (Fig. 6b). A clear tendency can be seen that smaller disintegrated and comminuted I1 and I2 pellet particles are more circular (i.e., rounder) than coarser particles. Disintegrated and comminuted wood pellets have low aspect ratios, which increase with particle size. There is a notable difference in the average aspect ratio between I1 and I2 pellet particles (Fig. 6a), which decreases with smaller particle sizes. I2 pellet particles appear to be more elongated than I1 pellet particles indicated by lower aspect ratios. Differences may be related to the different wood properties, such as microstructure and strength. For example, the comminuted wood shape may depend on the shearing resistance in different wood directions [53]. To illustrate, a particle aspect ratio of about 0.5 indicates a 2D particle area about twice as long as wide. The particles hence appear to be rather a flake or cuboid-like than spherical, which was also observed by Momeni [11] and Trubetskaya et al. [36]. With 2D image analysis lacking the third dimension, Trubetskaya et al. [36] analyzed the thickness of wood pellets comminuted in a 
roller mill at Avedøre power plant. For particles with a width below $0.85 \mathrm{~mm}$, the thickness was found to be about 0.6 times the particle width. Larger particles $(0.85-1.14 \mathrm{~mm}) \mathrm{had}$ a thickness of about 0.4 times the particle width. Thus, an average wood particle comminuted in a power plant roller mill with a width $\left(x_{c, \min }\right)$ of $1 \mathrm{~mm}$ has a typical length $\left(F e_{\max }\right)$ of $2 \mathrm{~mm}$ and a thickness of about $0.4 \mathrm{~mm}$. An adequate geometric representation of a comminuted wood particle, e.g., for combustion modeling purposes, may be a flat cuboid (plate).

\subsection{Influence of airflow rate and classifier rotor speed}

The airflow rate was reduced, and the rotor speed was increased for comminuting $\mathrm{I} 2$ pellets, while dam ring height, milling table speed, $H G P$, and $\dot{m}_{\text {Pellet }}$ remained constant (Scenarios 6 and 7, Table 3). Overall, a finer comminuted product conveyed to the burners is expected by adjusting the rotor speed and $\dot{m}_{\text {Air }}$ [20]. The results are in good agreement with what was expected. Fig. 7 shows that the average dust PSD from the burner pipes shifts to the left at Scenario 6 compared to Scenario 7. The $d^{*}$ and $D 90$ values decrease by $27 \%$ and $14 \%$, respectively, indicating a smaller classifier cut size when comminuting I 2 pellets at Scenario 6. However, this is at the expense of a $26 \%$ higher $P$, a $25 \%$ higher SGEC and a $16 \%$ higher $\Delta p$, indicating a lower grinding efficiency. The $S G E C$ seems to vary with the comminuted product fineness (i.e., classifier cut size). Both the higher $P$ and higher $\Delta p$ may be attributed to a higher material layer on the milling bed. Decreasing $\dot{m}_{\text {Air }}$ reduces the drag force to the rotor. Thus, less coarse wood particles may be carried through the classifier, and instead, fall onto the milling table. The thicker milling bed corresponds to a longer particle residence time (higher circulation load) on the milling table. Thus, particles 
will experience more grinding actions under the roller, leading to a finer and wider PSD (lower RRBS $n$-value). Along with the increased rotor speed, only fine particles will be lifted into the rotor classifier by the airflow. On the other hand, a stronger airflow and reduced rotor speed lead to a faster emptying of the mill, and a shorter particle residence time on the milling table. The comminuted product PSD then becomes coarser and narrower (higher RRBS $n$-value). Derived shape factors were similar to those shown in section 3.4. To attribute the individual contribution to the product fineness and absorbed mill power, the adjustments of airflow rate and the rotor speed need to be tested independently.

\subsection{Influence of mill load and airflow rate}

The general concept in modern CHP plants is to adjust the mill load (i.e., mill productivity) according to the needs of the boiler. A measure of the mill load is the pellet feed rate to the mill. More pellets entering the mill will increase the mill load, and hence the production rate. A higher $\dot{m}_{\text {Pellet }}$ means more material on the milling table, thus increasing the milling bed thickness that will lead to a higher $\Delta p$ (Table 7). This expectation is supported by a very strong positive, but not statistically significant trend between $\dot{m}_{P e l l e t}$ and $\Delta p(\mathrm{r}=0.80$, $\mathrm{p}=0.058$ ), as shown in Table 8 . To compensate for a thicker milling bed that requires a higher grinding effort, $\dot{m}_{\text {Pellet }}$ was regulated along with $H G P$. Thus, the $H G P$ provided by the spring-loaded roller system increases with a higher $\dot{m}_{\text {Pellet }}$ (i.e., thicker milling bed) and vice versa (Table 3). The Pearson's correlation coefficient of $r=1.00(p<0.001)$ confirms that there is a perfect linear relationship between $\dot{m}_{\text {Pellet }}$ and $H G P$ (Table 8). $H G P$ was also increased with the pellet feed rate to reduce the risk of mill choking (i.e., a 
situation that occurs when $\Delta p$ exceeds a threshold). Besides increasing $H G P, \dot{m}_{\text {Air }}$ was also regulated in a strong linear manner with $\dot{m}_{\text {Pellet }}(\mathrm{r}=0.90, \mathrm{p}<0.05)$. The greater amount of comminuted material in the mill requires a greater airflow volume for its transport through the classifier separation zone.

Table 7 shows the influence of various mill loads on the milling performance of I1 and I2 pellets. The general trend shows that a lower power consumption was achieved for a lower $\dot{m}_{\text {Pellet }}$. The power required for comminuting I1 and I2 pellets decreased from $213.6 \mathrm{~kW}$ at $20.4 \mathrm{t} / \mathrm{h}$ to $190.7 \mathrm{~kW}$ at $14.4 \mathrm{t} / \mathrm{h}$ for I1 pellets and from $228.9 \mathrm{~kW}$ at $20.6 \mathrm{t} / \mathrm{h}$ to $178.5 \mathrm{~kW}$ at $14.3 \mathrm{t} / \mathrm{h}$ for I2 pellets, respectively. This is because the resistance of the roller moving through the milling bed decreases, as the milling bed thickness reduces. The correlation matrix in Table 8 confirms that there is a statistically significant positive relationship between $P$ and $\dot{m}_{\text {Pellet }}(\mathrm{r}=0.88, \mathrm{p}<0.05)$. Being the most power-consuming unit of the CHP plant, the $S G E C$ is a suitable indicator of the grinding efficiency. When operating at higher loads, the roller mills achieve a lower SGEC (Table 7), hence indicating a higher grinding efficiency. A statistically significant negative correlation $(\mathrm{r}=-0.94, \mathrm{p}<0.01)$ was found between $S G E C$ and $\dot{m}_{\text {Pellet }}$ (Table 8). On the other hand, Von Rittinger's $K_{R}$ increased with $\dot{m}_{\text {Pellet }}(\mathrm{r}=0.92$, $\mathrm{p}<0.01)$. Consequently, the larger the difference between the feed PSD and the product PSD, the higher the grinding energy, which is in agreement with Von Rittinger's comminution theory.

At high $H G P$, particles theoretically experience more destructive breakage with the development of a finer product that is lifted through the classifier out to the burner pipes [29]. However, this could not be observed in this study. Instead, the increase in the $\dot{m}_{\text {Air }}$ may be a 
more dominant factor to affect the classifier cut size, thus resulting in a coarser final comminuted pellet product originating from a decreased classifier separation (Fig. 8). Higher $d^{*}$ and $D 90$ values in Table 7 indicate a reduced residence time (lower circulation load) of the pellet material in the mill. Wood particles experience fewer roller-grinding actions, which lead to a coarser comminuted product. This is due to the increased airflow that provides a higher airspeed to sweep away coarser particles to the classifier. Hence, the classifier cut size increases with increasing mill airflow rate. Consequently, at lower airflow rates, the classifier cut size decreases, and the comminuted product becomes finer. There exists a critical particle size below which it is impossible to comminute the particle further by compressive forces [56]. However, values are unknown for wood material, and they will vary between wood species due to their complex compression failure modes and different chemical composition [17].

Generally, at all airflow rates, a wider wood dust PSD (lower RRBS $n$-value) was observed compared to disintegrated pellets. The dust PSD became wider (lower RRBS $n$-value) with a decreasing mill airflow rate. The lower the RRBS $n$-value, the finer the comminuted product. The results of the particle shape characterization for disintegrated I1 and I 2 pellets compared to I1 and I2 pellets comminuted at various mill loads are shown in Supplementary Fig. S1 and S2. Overall, mill load changes had a negligible effect on the original elongated wood particle shape. Thus, VRMs regardless of their load do not seem to alter the wood particle shape. 


\subsection{Implications for power plant operators and wood pellet producers}

This paper provides an understanding of the roller mill operation and knowledge about the large-scale comminuted wood pellet characteristics (product fineness, shape, PSD). The obtained results may be a valuable basis for plant operators who wish to convert their existing coal plants to burn wood pellets. The accurate characterization of the comminuted product in power plants is crucial to optimize the milling and classifier performance, hence achieving an efficient and homogeneous wood combustion in a suspension-fired boiler. Sieve analysis, which is limited to the measurement of only one single dimension (i.e., particle width) may be rudimentary and should be replaced by an image analysis system suitable to characterize the comminuted product fineness and shape.

To achieve the desired comminuted product fineness (i.e., classifier cut size), plant operators should be aware that the internal PSD of pellets is a decisive pellet specification. Fig. 9 shows the average $S G E C$ for the tested milling scenarios from M20 versus the classifier cut size indicated by the $D 90$ value. It is clear that, on average, the comminution of I1 pellets leads to a finer comminuted product inside the burner pipes at a lower SGEC compared to I2 pellets. The milling scenario 5 gave the best grinding efficiency for I1 pellets indicated by the lowest $S G E C$ and smallest $D 90$. This indicates that the mill/air ratio of 2.3 seems to be ideal for comminuting pellets with a finer internal PSD. For comminuting 12 pellets, the milling scenario 9 may be the optimal choice to achieve the desired product fineness, however, accepting a higher SGEC. The geometric representation of the comminuted wood particles can be also valuable for combustion modeling, assuming a flat cuboid geometry. 
The study also found that roller mills have a negligible effect on the particle shape. This suggests that the pellet production process and/or the size reduction of the raw material before pelletization may define the shape of comminuted particles for suspension-firing. The particle shape may be furthermore affected by the microstructure of wood material, which is used for pelletization. The proper choice of wood species for pelletization may yield the desired shape of comminuted particles.

\section{Conclusions}

The large-scale milling behavior of two industrial wood pellet qualities in coal roller mills, equipped with dynamic classifiers, at a suspension-fired power plant was investigated. The following conclusions can be drawn from the experimental study:

- The size distribution of comminuted wood pellets by sieve analysis and Camsizer ${ }^{\circledR} \mathrm{X} 2$ (X-Jet mode) can be well fit with the Rosin-Rammler-BennetSperling model.

- Isokinetic wood dust sampling from vertical and symmetric mill outlet pipes is the preferred sampling method. Sampling from horizontal pipes increases the risk of particle segregation. Sampling from asymmetric pipes shows a more uneven wood dust distribution regarding fineness and mass flow of the comminuted particles.

- The internal particle size distribution of wood pellets affects the large-scale pellet milling behavior and the subsequent particle size classification (i.e., classifier cut size). Pellets with finer internal particles lead to a finer comminuted product (smaller cut size) with lower specific grinding energy consumption. 
- Roller mills do not affect the original elongated wood particle shape, regardless of the mill operating conditions. Differences in the aspect ratios of comminuted and internal particles from different pellet qualities are probably explained by the wood microstructure in the pellet.

- The operation of the roller mill at higher loads and higher primary airflow rates has unfavorable effects on the mill power consumption, the differential mill pressure, and the classifier cut size. Only the specific energy consumption can be reduced, when the mill operates at higher loads.

- The specific energy consumption for pellet comminution varies with the classifier cut size. At a constant mill load, an increased rotor speed and a reduced airflow rate lead to a smaller classifier cut size. However, this is at the expense of a higher energy consumption and a higher differential mill pressure.

\section{Nomenclature \\ $\dot{\mathrm{m}}_{\text {Air }} \quad$ airflow rate to the mill $(\mathrm{t} / \mathrm{h})$ \\ $\dot{\mathrm{m}}_{\text {Dust }} \quad$ wood dust sample flow $(\mathrm{g} / \mathrm{s})$ \\ $\dot{\mathrm{m}}_{\text {Pellet }}$ fresh wood pellet feed rate $(\mathrm{t} / \mathrm{h})$ \\ A Particle particle projection area $\left(\mathrm{mm}^{2}\right)$ \\ $\mathrm{m}_{\text {Pellet }}$ amount of wood pellets $(\mathrm{t})$ \\ $\mathrm{P}_{\text {Particle }}$ particle perimeter $(\mathrm{mm})$ \\ $\Delta \mathrm{p} \quad$ differential mill pressure $(\mathrm{kPa})$ \\ AMV Amagerværket (Amager power station) \\ AR particle aspect ratio (dimensionless) \\ ar as received \\ C circularity (dimensionless)}




\begin{tabular}{|c|c|}
\hline $\mathrm{CHP}$ & combined heat and power \\
\hline$d$ & particle size (mm) \\
\hline $\mathrm{D}$ & pellet diameter (mm) \\
\hline$d^{*}$ & RRBS characteristic particle size (mm) \\
\hline d.b. & dry basis \\
\hline D90 & particle size at 90th percentile of the \\
\hline & cumulative undersize distribution (mm) \\
\hline $\mathrm{d}_{\mathrm{f}}$ & 90th percentile feed passing size $(\mathrm{mm})$ \\
\hline $\mathrm{D}_{\mathrm{N}}$ & nominal milling table diameter (m) \\
\hline DP & diameter milling path $(\mathrm{m})$ \\
\hline$d_{\mathrm{p}}$ & 90th percentile product passing size (mm) \\
\hline $\mathrm{Fe}_{\max }$ & maximum Feret diameter $(\mathrm{mm})$ \\
\hline HGP & hydraulic grinding pressure $(\mathrm{MPa})$ \\
\hline $\mathrm{K}_{\mathrm{R}}$ & $\begin{array}{l}\text { Von Rittinger's material characteristic } \\
\text { parameter }\left(\mathrm{kWh} \mathrm{mm} \mathrm{t}^{-1}\right)\end{array}$ \\
\hline $\mathrm{L}$ & pellet length (mm) \\
\hline M10 & mill 10 \\
\hline M20 & mill 20 \\
\hline M30 & mill 30 \\
\hline $\mathrm{n}$ & RRBS uniformity constant (dimensionless) \\
\hline $\mathrm{P}$ & absorbed mill power $(\mathrm{kW})$ \\
\hline PSD & particle size distribution \\
\hline $\mathrm{R}(\mathrm{d})$ & cumulative undersize distribution $(\%)$ \\
\hline RRBS & Rosin-Rammler-Bennet-Sperling \\
\hline SGEC & specific grinding energy consumption $(\mathrm{kWh} / \mathrm{t})$ \\
\hline VRM & vertical roller mill \\
\hline w.b. & wet basis \\
\hline wt. $\%$ & weight percent \\
\hline $\mathrm{xc}, \min$ & shortest maximum chord (mm) \\
\hline
\end{tabular}




\section{Acknowledgements}

The authors thank Energinet.dk for the financial support received as part of the ForskEL project “AUWP - Advanced Utilization of Wood Pellets" (Project number: 12325). The authors wish also to thank and acknowledge all those involved for their considerable support and contribution to the study.

\section{Appendix A. Supplementary data}

Supplementary data associated with this article can be found in the online version.

\section{References}

[1] M. Cocchi, L. Nikolaisen, M. Junginger, C.S. Goh, R. Hess, J. Jacobson, L.P. Ovard, D. Thrän, C. Hennig, M. Deutmeyer, P.P. Schouwenberg, Global wood pellet industry market and trade study, IEA Bioenergy Task 40: "Sustainable Bioenergy Trade." (2011) 6-10. https://www.nachhaltigwirtschaften.at/resources/iea_pdf/reports/iea_task40_wood_p ellet_industry_market.pdf (accessed August 8, 2017).

[2] S. Döring, Power from pellets: technology and applications, 1st ed., Springer-Verlag Berlin Heidelberg, 2013. doi:10.1007/978-3-642-19962-2.

[3] G. Eskeland, N. Rive, T. Mideksa, The 2020 European climate goals and the electricity sector, 11th Annual Conference on Global Economic Analysis, Helsinki, Finland. (2008) 1-2. doi:10.1016/j.enpol.2011.10.038.

[4] M. Grbovic, Export potential of U.S. - produced switchgrass and wood pellets for the EU market (Master's thesis), University of Tennessee, USA, 2010.

[5] S. Caillat, E. Vakkilainen, Biomass Combustion Science, Technology and 
Engineering, 1st ed., Woodhead Publishing Limited, 2013.

doi:10.1533/9780857097439.3.189.

[6] P. Gilbert, C. Ryu, V. Sharifi, J. Swithenbank, Effect of process parameters on pelletisation of herbaceous crops, Fuel. 88 (2009) 1491-1497.

doi:10.1016/j.fuel.2009.03.015.

[7] P. Lehtikangas, Storage effects on pelletised sawdust, logging residues and bark, Biomass and Bioenergy. 19 (2000) 287-293. doi:10.1016/S0961-9534(00)00046-5.

[8] W.R. Livingston, The status of large scale biomass firing: The milling and combustion of biomass materials in large pulverised coal boilers, IEA Bioenergy Task 32: Biomass Combustion and Co-Firing. (2016) 21-23.

[9] M. Odenberger, The role of combustion in the future energy system, Keynote Presentation at the Nordic Flame Days, in: Stockholm, Sweden, 2017.

[10] L.S. Esteban, J.E. Carrasco, Evaluation of different strategies for pulverization of forest biomasses, 166 (2006) 139-151. doi:10.1016/j.powtec.2006.05.018.

[11] M. Momeni, Fundamental study of single biomass particle combustion ( $\mathrm{PhD}$ Thesis), Department of Energy Technology, Aalborg University, Denmark, 2012.

[12] A. Trubetskaya, Y. Poyraz, R. Weber, J. Wadenbäck, Secondary comminution of wood pellets in power plant and laboratory-scale mills, Fuel Processing Technology. 160 (2017) 216-227. doi:10.1016/j.fuproc.2017.02.023.

[13] S.A. Martin, Comparison of hammermill and roller mill grinding and the effect of grain particle size on mixing and pelleting (Master's thesis), Kansas State 
University, USA, 1985.

[14] M. Temmerman, P.D. Jensen, J. Hébert, Von Rittinger theory adapted to wood chip and pellet milling, in a laboratory scale hammermill, Biomass and Bioenergy. 56 (2013) 70-81. doi:10.1016/j.biombioe.2013.04.020.

[15] S. Mani, L.G. Tabil, S. Sokhansanj, Grinding performance and physical properties of wheat and barley straws, corn stover and switchgrass, Biomass and Bioenergy. 27 (2004) 339-352. doi:10.1016/j.biombioe.2004.03.007.

[16] A. Malmgren, Talking about the revolution, World Coal. (2015) 1-4. http://www.bioc-ltd.com/images/Talking_about_the_revolution-World_CoalNov_2015.pdf (accessed June 8, 2017).

[17] O. Williams, G. Newbolt, C. Eastwick, S. Kingman, D. Giddings, S. Lormor, E. Lester, Influence of mill type on densified biomass comminution, Applied Energy. 182 (2016) 219-231. doi:10.1016/j.apenergy.2016.08.111.

[18] C. Yin, Biomass co-firing, in: Biomass Combustion Science, Technology and Engineering, Elsevier Science \& Technology, Cambridge, UK, 2013: pp. 84-105. doi:10.1533/9780857097439.3.189.

[19] M.A. Saeed, G.E. Andrews, H.N. Phylaktou, B.M. Gibbs, Global kinetics of the rate of volatile release from biomasses in comparison to coal, Fuel. 181 (2016) 347-357. doi:10.1016/j.fuel.2016.04.123.

[20] G.G. Mejeoumov, Improved cement quality and grinding efficiency by means of closed mill circuit modeling (PhD thesis), Texas A\&M University, USA, 2007. 
[21] O. Altun, H. Benzer, Selection and mathematical modelling of high efficiency air classifiers, Powder Technology. 264 (2014) 1-8. doi:10.1016/j.powtec.2014.05.013.

[22] E. Ortega-Rivas, Unit operations of particulate solids: theory and practice, CRC Press, 2011.

[23] N. Paul, S. Biggs, J. Shiels, R.B. Hammond, M. Edmondson, L. Maxwell, D. Harbottle, T.N. Hunter, Influence of shape and surface charge on the sedimentation of spheroidal, cubic and rectangular cuboid particles, Powder Technology. 322 (2017) 75-83. doi:10.1016/j.powtec.2017.09.002.

[24] J.L. Afolabi, The performance of a static coal classifier and its controlling parameters. PhD thesis, University of Leicester, UK. (2012).

[25] T.N. Adams, D.R. Raymond, C. Schmid, Optimization of a swirl burner for pulverized- wood fuels, Tappi. 71-5 (1988) 91-96.

[26] International Organization for Standardization, ISO 17225-2:2014 Solid biofuels Fuel specifications and classes - Part 2: Graded wood pellets, (2014) 7-8.

[27] International Organization for Standardization, ISO 17830:2016 Solid biofuels Particle size distribution of disintegrated pellets, (2014) 1-8.

[28] M. Schmidt, Two products from a single grinding mill, Mineral Processing. 54 (2013) 3-14.

[29] S. Palaniandy, N.A. Kadir, M. Jaafar, Value adding limestone to filler grade through an ultra-fine grinding process in jet mill for use in plastic industries, Minerals Engineering. 22 (2009) 695-703. doi:10.1016/j.mineng.2009.02.010. 
[30] T. Fahrland, K.H. Zysk, Cements ground in the vertical roller mill fulfil the quality requirements of the market, Cement International. 11 (2013) 64-69.

[31] D. Altun, H. Benzer, N. Aydogan, C. Gerold, Operational parameters affecting the vertical roller mill performance, Minerals Engineering. 103-104 (2017) 67-71. doi:10.1016/j.mineng.2016.08.015.

[32] International Organization for Standardization, ISO 14488:2007 Particulate materials - Sampling and sample splitting for the determination of particulate properties, (2007) 11.

[33] J.R. Coombes, Y. Yan, Experimental investigations into the flow characteristics of pneumatically conveyed biomass particles using an electrostatic sensor array, Fuel. 151 (2015) 11-20. doi:10.1016/j.fuel.2014.11.048.

[34] D. Lindsley, Power Plant Control and Instrumentation: the control of boilers and HRSG systems, The Institution of Engineering and Technology, 2000. doi:10.1049/PBCE058E.

[35] Retsch Technology GmbH, CAMSIZER ${ }^{\circledR}$ Characteristics, (2009) 8. http://www.horiba.com/fileadmin/uploads/Scientific/Documents/PSA/Manuals/CA MSIZER_Characteristics_Nov2009.pdf (accessed December 15, 2017).

[36] A. Trubetskaya, G. Beckmann, J. Wadenbäck, J.K. Holm, S.P. Velaga, R. Weber, One way of representing the size and shape of biomass particles in combustion modeling, Fuel. 206 (2017) 675-683. doi:10.1016/j.fuel.2017.06.052.

[37] D.A. Robinson, S.P. Friedman, Observations of the effects of particle shape and 
particle size distribution on avalanching of granular media, Physica A: Statistical Mechanics and Its Applications. 311 (2002) 97-110. doi:10.1016/S03784371(02)00815-4.

[38] W. Pichler, A. Weidenhiller, J. Denzler, R. Goetzl, M. Pain, M. Weigl, A. Haider, Approaches to describe the particle properties of wood pellet feedstock, World Bioenergy 2014, Jönköping, Sweden. (2014) 2-3. doi:10.13140/2.1.3203.3286.

[39] W. Pichler, A. Weidenhiller, J. Denzler, R. Goetzl, M. Pain, M. Weigl, A. Haider, Modelling the particle size distribution of the feedstock for pellets production, 22nd European Biomass Conference and Exhibition, Hamburg, Germany. (2014).

[40] M. Gil, I. Arauzo, Hammer mill operating and biomass physical conditions effects on particle size distribution of solid pulverized biofuels, Fuel Processing Technology. 127 (2014) 80-87. doi:10.1016/j.fuproc.2014.06.016.

[41] T. Allen, Powder Sampling and Particle Size Determination, 1st ed., Elsevier Science, Oxford, UK, 2003.

[42] G. V. Barbose-Cànovas, E. Ortega-Rivas, P. Juliano, H. Yan, Food Powders, Springer US, Boston, USA, 2005. doi:10.1007/0-387-27613-0.

[43] Y. Yu, R.R. Liu, J. Liu, Correspondence analysis and establishment of evaluation model of classification performance indices for a turbo air classifier, Materialwissenschaft Und Werkstofftechnik. 45 (2014) 900-911. doi:10.1002/mawe.201400249.

[44] T. Tanaka, Comminution Laws. Several Probabilities, Industrial \& Engineering 
Chemistry Process Design and Development. 5 (1966) 353-358.

doi:10.1021/i260020a001.

[45] O. Williams, E. Lester, S. Kingman, D. Giddings, S. Lormor, C. Eastwick, Benefits of dry comminution of biomass pellets in a knife mill, Biosystems Engineering. 160 (2017) 42-54. doi:10.1016/j.biosystemseng.2017.05.011.

[46] J.D. Wilcox, Isokinetic Flow and Sampling, Journal of the Air Pollution Control Association. 5 (1956) 226-245. doi:10.1080/00966665.1956.10467715.

[47] X. Qian, Y. Yan, Flow measurement of biomass and blended biomass fuels in pneumatic conveying pipelines using electrostatic sensor-arrays, IEEE Transactions on Instrumentation and Measurement. 61 (2012) 1343-1352. doi:10.1109/TIM.2011.2175034.

[48] L. Cai, C. Jiaying, X. Guiling, X. Pan, C. Xiaoping, Z. Changsui, Experimental investigation and stability analysis on dense-phase pneumatic conveying of coal and biomass at high pressure, Korean Journal of Chemical Engineering. 30 (2013) 295305. doi:10.1007/s11814-012-0165-2.

[49] J. Tomas, S. Kleinschmidt, Improvement of flowability of fine cohesive powders by flow additives, Chemical Engineering and Technology. 32 (10) (2009) 1470-1483. doi:10.1002/ceat.200900173.

[50] S. Kwon, G.L. Messing, The effect of particle solubility on the strength of nanocrystalline agglomerates: Boehmite, Nanostructured Materials. 8 (1997) 399_418. doi:10.1016/S0965-9773(97)00180-3. 
[51] P. Daugbjerg Jensen, M. Temmerman, S. Westborg, Internal particle size distribution of biofuel pellets, Fuel. 90 (2011) 980-986. doi:10.1016/j.fuel.2010.11.029.

[52] H. Rezaei, C.J. Lim, A. Lau, S. Sokhansanj, Size, shape and flow characterization of ground wood chip and ground wood pellet particles, Powder Technology. 301 (2016) 737-746. doi:10.1016/j.powtec.2016.07.016.

[53] Q. Guo, X. Chen, H. Liu, Experimental research on shape and size distribution of biomass particle, Fuel. 94 (2012) 551-555. doi:10.1016/j.fuel.2011.11.041.

[54] C. Wagner, K.H. Esbensen, Representative Sampling of Suspended Particulate Materials in Horizontal Ducted Flow: Evaluating the Prototype "EF-sampler," Journal of Chemical Engineering \& Process Technology. 3 (2012). doi:10.4172/2157-7048.1000139.

[55] H. Archary, W. Schmitz, L. Jestin, Mass flow and particle size monitoring of pulverised fuel vertical spindle mills, Chemical and Process Engineering - Inzynieria Chemiczna I Procesowa. 37 (2016) 175-197. doi:10.1515/cpe-2016-0016.

[56] K. Kendall, The impossibility of comminuting small particles by compression, Nature. 272 (1978) 710-711. doi:10.1038/272710a0.

[57] Cement seminar: process technology (roller mills), Holderbank Management \& Consulting. (1993) 1-14. http://222.255.19.250/picture/PRJMEC/VAN/Holcim/Raw Grinding Systems.pdf (accessed July 18, 2017). 


\section{Figure captions}

Fig. 1: Schematic representation of a large-scale coal VRM and the internal material flow within the mill. Adapted from [57].

Fig. 2: Mill-burner configuration at AMV1.

Fig. 3: Comminuted pellet sampled from M20 burner pipes PSDs and RRBS fit parameters $\mathrm{n}$ and $\mathrm{d}^{*}$, and D90 analyzed by sieving and Camsizer® X2 (Scenario 2, Table 3). Error bars indicate the $95 \%$ confidence interval of three repeated measurements.

Fig. 4: Vertical versus horizontal pipe sampling of comminuted I1 pellets (Scenarios 2-4, Table 3). Each line represents the average PSD of four burner pipes of that mill. Error bars show one standard deviation within the different fuel pipes of the same mill.

Fig. 5: PSD comparison between disintegrated and comminuted pellets (Scenarios 5 and 6, Table 3). Error bars represent one standard deviation within the different fuel pipes of the mill, and they are displayed when greater than the data symbol.

Fig. 6: Average aspect ratio (a) and circularity (b) of disintegrated and comminuted I1 and I2 pellets (Scenarios 5 and 6, Table 3). Error bars indicate one standard deviation within different fuel pipes of the mill, and they are displayed when greater than the data symbol.

Fig. 7: Average cumulative PSD of I2 pellets comminuted at different airflow rates and rotor speeds (Scenarios 6 and 7, Table 3). Error bars represent one standard deviation within the different fuel pipes of the mill. 
Fig. 8: Average cumulative PSD of disintegrated I1 pellets (a) and I2 pellets (b) in comparison to I1 pellets comminuted at different airflow rates (Scenarios 7-12, Table 3). Error bars indicate one standard deviation within the different fuel pipes of the mill, and they are displayed when greater than the data symbol.

Fig. 9: Specific energy consumption for comminuting I1 and I2 pellets at different steady state conditions as a function of the classifier cut size indicated by the $D 90$ value. 


\section{Tables and Figures}

Table 1: Specifications of the two industrial wood pellet qualities graded according to ISO 17225-2:2014 [26].

\begin{tabular}{|c|c|c|c|c|}
\hline Parameters & Unit & I1 Pellets & I2 Pellets & Method \\
\hline \multicolumn{5}{|l|}{ Proximate analysis } \\
\hline Moisture content & wt. $\%$, ar, w.b. & 6.6 & 5.7 & EN ISO 18134-1: 2015 \\
\hline Ash content & wt. $\%$, d.b. & 0.6 & 0.6 & EN ISO 18122: 2015 \\
\hline Volatile matter & wt. $\%$, d.b. & 84.5 & 83.9 & EN ISO 18123: 2015 \\
\hline Fixed carbon & wt. $\%$, d.b. & 14.9 & 15.5 & By difference \\
\hline \multicolumn{5}{|l|}{ Ultimate analysis } \\
\hline Carbon & wt. $\%$, d.b. & 50.7 & 51.1 & EN ISO 16948: 2015 \\
\hline Nitrogen & wt. $\%$, d.b. & 0.2 & 0.1 & EN ISO 16948: 2015 \\
\hline Hydrogen & wt. $\%$, d.b. & 6.1 & 6.1 & EN ISO 16948: 2015 \\
\hline Oxygen & wt. $\%$, d.b. & 42.4 & 42.0 & $\begin{array}{l}\text { EN 14588:2010 } \\
\text { (by difference) }\end{array}$ \\
\hline $\begin{array}{l}\text { Net calorific } \\
\text { value }\end{array}$ & $\mathrm{MJ} / \mathrm{kg}$, ar & 17.5 & 18.0 & EN 14918: 2009 \\
\hline $\begin{array}{l}\text { Pellet diameter } \\
\text { (D) and length (L) }\end{array}$ & $\mathrm{mm}$, ar & $\begin{array}{l}\mathrm{D}, 6.2 \text { and } 8.3 ; \\
\mathrm{L}, 12.3\end{array}$ & $\begin{array}{l}\mathrm{D}, 6.7 \\
\mathrm{~L}, 12.9\end{array}$ & EN ISO 17829: 2015 \\
\hline Bulk density & $\begin{array}{l}\mathrm{kg} / \mathrm{m} 3 \text {, as } \\
\text { received }\end{array}$ & 653.1 & 669.2 & EN ISO 17828: 2015 \\
\hline $\begin{array}{l}\text { Mechanical } \\
\text { durability (fines) }\end{array}$ & wt. $\%$, ar & 98.5 & 99.1 & EN ISO 17831-1: 2015 \\
\hline $\begin{array}{l}\text { PSD of } \\
\text { disintegrated }\end{array}$ & wt. $\%$, d.b. & $\begin{array}{l}\geq 99.5 \% \\
(<3.15 \mathrm{~mm})\end{array}$ & $\begin{array}{l}\geq 98.0 \% \\
(<3.15 \mathrm{~mm})\end{array}$ & EN ISO 17830: 2016 \\
\hline pellets (internal & & $\geq 98.7 \%$ & $\geq 93.9 \%$ & \\
\hline PSD) & & $(<2.0 \mathrm{~mm})$ & $(<2.0 \mathrm{~mm})$ & \\
\hline & & $\geq 79.2 \%$ & $\geq 59.4 \%$ & \\
\hline & & $(<1.0 \mathrm{~mm})$ & $(<1.0 \mathrm{~mm})$ & \\
\hline
\end{tabular}


Table 2: Technical specifications of the three Loesche coal VRMs.

\begin{tabular}{ll}
\hline Description & Specification \\
\hline Throughput rate (t/h) & Up to 36 (for coal) \\
& Up to 28.8 (for biomass) \\
Number of rollers & 2 \\
Roller inclination & $15^{\circ}$ \\
Nominal milling table diameter (m), $\mathrm{D}_{\mathrm{N}}$ & 1.9 \\
Diameter milling path $(\mathrm{m}), \mathrm{D}_{\mathrm{P}}$ & 1.5 \\
Milling table speed $(\mathrm{rpm})$ & 42 \\
Motor drive power $(\mathrm{kW})$ & 315 \\
Separator & Dynamic classifier \\
\hline
\end{tabular}


Table 3: Operating conditions of the mill-classifier system for various test scenarios ${ }^{1}$.

\begin{tabular}{llllllll}
\hline$\#$ & Mill & Pellets & $\begin{array}{l}\dot{\mathrm{m}}_{\text {Pellet }} \\
(\mathrm{t} / \mathrm{h})\end{array}$ & $\begin{array}{l}\dot{\mathrm{m}}_{\text {Air }} \\
(\mathrm{t} / \mathrm{h})\end{array}$ & $\begin{array}{l}\text { Mill air/fuel } \\
\text { ratio }^{2}\end{array}$ & $\begin{array}{l}\text { Rotor speed }^{3} \\
(\%)\end{array}$ & $\begin{array}{l}\text { HGP } \\
(\mathrm{MPa})\end{array}$ \\
\hline 1 & M30 & I1 & 28.8 & 56.8 & 2.0 & 13.1 & 7.0 \\
2 & M10 & I1 & 20.5 & 46.8 & 2.3 & 17.2 & 6.6 \\
3 & M20 & I1 & 20.4 & 46.5 & 2.3 & 17.7 & 6.5 \\
4 & M30 & I1 & 20.3 & 46.4 & 2.3 & 17.4 & 6.5 \\
5 & M20 & I1 & 20.6 & 46.8 & 2.3 & 17.4 & 6.6 \\
6 & M20 & I2 & 20.6 & 46.7 & 2.3 & 17.5 & 6.7 \\
7 & M20 & I2 & 20.6 & 52.2 & 2.5 & 13.0 & 6.7 \\
8 & M20 & I2 & 16.6 & 43.7 & 2.6 & 13.0 & 6.3 \\
9 & M20 & I2 & 14.3 & 41.2 & 2.9 & 13.0 & 6.1 \\
10 & M20 & I1 & 20.5 & 46.5 & 2.3 & 17.6 & 6.7 \\
11 & M20 & I1 & 17.4 & 43.0 & 2.5 & 16.6 & 6.4 \\
12 & M20 & I1 & 14.4 & 39.6 & 2.7 & 15.7 & 6.1 \\
\hline
\end{tabular}

${ }^{1}$ Dam ring height and milling table speed are constant.

${ }^{2}$ Mill air/fuel ratio is the ratio of primary airflow rate to pellet feed rate into the VRM.

${ }^{3}$ Rotor speed is given as the percentage of the maximum speed. 
Table 4: Measured range of mill operational parameters and the sensors used.

\begin{tabular}{lll}
\hline Parameter & Range & Sensor type \\
\hline$\dot{\mathrm{m}}_{\text {Pellet }}(\mathrm{t} / \mathrm{h})$ & $14.3-28.8$ & Load cell \\
$\dot{\mathrm{m}}_{\text {Air }}(\mathrm{t} / \mathrm{h})$ & $39.6-56.8$ & Pitot tube + pressure transducer \\
Classifier rotator speed $(\%)^{1}$ & $13.0-17.7$ & Proximity switch \\
$\Delta \mathrm{p}(\mathrm{kPa})$ & $2.0-3.8$ & Pressure transducer \\
Mill inlet temperature set point $\left({ }^{\circ} \mathrm{C}\right)$ & 130 & PT 100 + transducer \\
Mill exit temperature set point $\left({ }^{\circ} \mathrm{C}\right)$ & 60 & PT $100+$ transducer \\
HGP $(\mathrm{MPa})$ & $6.1-7.0$ & Force transducer \\
Motor power $(\mathrm{kW})$ & $178.5-287.3$ & Torque transducer \\
\hline
\end{tabular}

${ }^{1}$ Rotor speed is given as the percentage of the maximum speed. 
Table 5: Dust flow characteristics in the burner pipes exiting M30 (Scenario 1, Table 3). Average values from five samples and their $95 \%$ confidence interval indicated in parentheses. Particle size analysis was performed by mechanical sieving.

\begin{tabular}{lllll}
\hline \# Pipe & $\begin{array}{l}\text { Wood dust sample flow } \\
\dot{\mathrm{m}}_{\text {Dust }}(\mathrm{g} / \mathrm{s})^{1}\end{array}$ & $\mathrm{n}$ & $\begin{array}{l}\mathrm{d}^{*} \\
(\mathrm{~mm})\end{array}$ & $\begin{array}{l}\mathrm{D} 90 \\
(\mathrm{~mm})\end{array}$ \\
\hline 1 & $1.31(0.08)^{\mathrm{a}}$ & $0.93(0.05)^{\mathrm{a}}$ & $0.38(0.02)^{\mathrm{a}}$ & $0.94(0.01)^{\mathrm{a}}$ \\
2 & $3.31(0.24)^{\mathrm{b}}$ & $1.18(0.06)^{\mathrm{b}}$ & $0.59(0.03)^{\mathrm{b}}$ & $1.18(0.04)^{\mathrm{b}}$ \\
3 & $2.77(0.21)^{\mathrm{c}}$ & $1.18(0.05)^{\mathrm{b}}$ & $0.53(0.03)^{\mathrm{c}}$ & $1.02(0.04)^{\mathrm{c}}$ \\
4 & $5.11(0.16)^{\mathrm{d}}$ & $1.26(0.02)^{\mathrm{c}}$ & $0.67(0.01)^{\mathrm{c}}$ & $1.27(0.02)^{\mathrm{d}}$ \\
\hline
\end{tabular}

${ }^{1}$ The amount of wood dust sampled divided by the sampling time.

Note: different letters on average values in the same column indicate statistical significance at $5 \%$. 
Table 6: Milling performance and PSD characteristics of comminuted I1 and I2 pellets sampled from M20 burner pipes compared to disintegrated I1 and I2 pellets. Average values are presented and one standard deviation between fuel pipes is indicated in parentheses.

\begin{tabular}{llllllll}
\hline & $\mathrm{n}$ & $\begin{array}{l}\mathrm{d}^{*} \\
(\mathrm{~mm})\end{array}$ & $\begin{array}{l}\mathrm{D} 90 \\
(\mathrm{~mm})\end{array}$ & $\begin{array}{l}\mathrm{K}_{\mathrm{R}} \\
(\mathrm{kWh} \mathrm{mm} / \mathrm{t})\end{array}$ & $\begin{array}{l}\mathrm{P} \\
(\mathrm{kW})\end{array}$ & $\begin{array}{l}\mathrm{SGEC}^{1} \\
(\mathrm{kWh} / \mathrm{t})\end{array}$ & $\begin{array}{l}\Delta \mathrm{p} \\
(\mathrm{kPa})\end{array}$ \\
\hline Comminuted I1 & $0.97^{\mathrm{a}}$ & $0.50^{\mathrm{a}}$ & $1.22^{\mathrm{a}}$ & $60.9^{\mathrm{a}}$ & $197.5^{\mathrm{a}}$ & $9.6^{\mathrm{a}}$ & $3.4^{\mathrm{a}}$ \\
pellets (Scenario 5) & $(0.03)$ & $(0.10)$ & $(0.07)$ & & $(3.1)$ & & $(0.2)$ \\
Disintegrated I1 & $1.37^{\mathrm{b}}$ & $0.83^{\mathrm{b}}$ & $1.51^{\mathrm{b}}$ & & & & \\
pellets & $(0.06)$ & $(0.01)$ & $(0.01)$ & & & & \\
Comminuted I2 & $0.97^{\mathrm{a}}$ & $0.56^{\mathrm{a}}$ & $1.39^{\mathrm{c}}$ & $81.8^{\mathrm{b}}$ & $287.3^{\mathrm{b}}$ & $13.9^{\mathrm{a}}$ & $4.4^{\mathrm{b}}$ \\
pellets (Scenario 6) & $(0.08)$ & $(0.13)$ & $(0.07)$ & & $(3.3)$ & & $(0.1)$ \\
Disintegrated I2 & $1.40^{\mathrm{b}}$ & $1.09^{\mathrm{c}}$ & $1.82^{\mathrm{d}}$ & & & & \\
pellets & $(0.01)$ & $(0.04)$ & $(0.02)$ & & & & \\
\hline
\end{tabular}

${ }^{1}$ Dynamic classifier and fan power not included in SGEC.

Note: different letters on average values in the same column indicate statistical significance at $5 \%$. 
Table 7: Effect of pellet feed rate on the milling performance. Average values are presented, and one standard deviation between pipes is indicated in parentheses.

\begin{tabular}{|c|c|c|c|c|c|c|c|c|c|}
\hline & $\begin{array}{l}\dot{\mathrm{m}}_{\text {Pellet }} \\
(\mathrm{t} / \mathrm{h})\end{array}$ & $\begin{array}{l}\dot{\mathrm{m}}_{\text {air }} \\
(\mathrm{t} / \mathrm{h})\end{array}$ & $\mathrm{n}$ & $\begin{array}{l}d^{*} \\
(\mathrm{~mm})\end{array}$ & $\begin{array}{l}\text { D90 } \\
(\mathrm{mm})\end{array}$ & $\begin{array}{l}\mathrm{K}_{\mathrm{R}} \\
(\mathrm{kWh} \mathrm{mm} / \mathrm{t})\end{array}$ & $\begin{array}{l}\mathrm{P} \\
(\mathrm{kW})\end{array}$ & $\begin{array}{l}\text { SGEC }^{\mathrm{a}} \\
(\mathrm{kWh} / \mathrm{t})\end{array}$ & $\begin{array}{l}\Delta \mathrm{p} \\
(\mathrm{kPa})\end{array}$ \\
\hline $\begin{array}{l}\text { Disintegrated } \\
\text { I1 pellets }\end{array}$ & & & $\begin{array}{l}1.37 \\
(0.06)\end{array}$ & $\begin{array}{l}0.83 \\
(0.01)\end{array}$ & $\begin{array}{l}1.51 \\
(0.01)\end{array}$ & & & & \\
\hline $\begin{array}{l}\text { Comminuted } \\
\text { I1 pellets } \\
\text { (Scenario 10) }\end{array}$ & 20.5 & 46.5 & $\begin{array}{l}0.96 \\
(0.04)\end{array}$ & $\begin{array}{l}0.57 \\
(0.07)\end{array}$ & $\begin{array}{l}1.34 \\
(0.04)\end{array}$ & 125.0 & $\begin{array}{l}213.6 \\
(1.9)\end{array}$ & 10.5 & 2.9 \\
\hline $\begin{array}{l}\text { Comminuted } \\
\text { I1 pellets } \\
\text { (Scenario 11) }\end{array}$ & 17.4 & 43.0 & $\begin{array}{l}0.93 \\
(0.01)\end{array}$ & $\begin{array}{l}0.53 \\
(0.03)\end{array}$ & $\begin{array}{l}1.29 \\
(0.08)\end{array}$ & 103.6 & $\begin{array}{l}204.2 \\
(1.5)\end{array}$ & 11.7 & 2.4 \\
\hline $\begin{array}{l}\text { Comminuted } \\
\text { I1 pellets } \\
\text { (Scenario 12) }\end{array}$ & 14.4 & 39.6 & $\begin{array}{l}0.87 \\
(0.04)\end{array}$ & $\begin{array}{l}0.41 \\
(0.03)\end{array}$ & $\begin{array}{l}1.14 \\
(0.11)\end{array}$ & 61.9 & $\begin{array}{l}190.7 \\
(3.1)\end{array}$ & 13.3 & 2.0 \\
\hline $\begin{array}{l}\text { Disintegrated } \\
\text { I } 2 \text { pellets }\end{array}$ & & & $\begin{array}{l}1.40 \\
(0.01)\end{array}$ & $\begin{array}{l}1.09 \\
(0.04)\end{array}$ & $\begin{array}{l}1.82 \\
(0.02)\end{array}$ & & & & \\
\hline $\begin{array}{l}\text { Comminuted } \\
\text { I2 pellets } \\
\text { (Scenario 7) }\end{array}$ & 20.6 & 52.2 & $\begin{array}{l}1.00 \\
(0.11)\end{array}$ & $\begin{array}{l}0.77 \\
(0.07)\end{array}$ & $\begin{array}{l}1.62 \\
(0.07)\end{array}$ & 163.9 & $\begin{array}{l}228.9 \\
(1.1)\end{array}$ & 11.1 & 3.8 \\
\hline $\begin{array}{l}\text { Comminuted } \\
\text { I2 pellets } \\
\text { (Scenario 8) }\end{array}$ & 16.6 & 43.7 & $\begin{array}{l}0.95 \\
(0.06)\end{array}$ & $\begin{array}{l}0.68 \\
(0.08)\end{array}$ & $\begin{array}{l}1.53 \\
(0.07)\end{array}$ & 111.4 & $\begin{array}{l}192.4 \\
(1.1)\end{array}$ & 11.6 & 2.8 \\
\hline $\begin{array}{l}\text { Comminuted } \\
\text { I } 2 \text { pellets } \\
\text { (Scenario 9) }\end{array}$ & 14.3 & 41.2 & $\begin{array}{l}0.88 \\
(0.07)\end{array}$ & $\begin{array}{l}0.46 \\
(0.08)\end{array}$ & $\begin{array}{l}1.20 \\
(0.09)\end{array}$ & 44.0 & $\begin{array}{l}178.5 \\
(1.2)\end{array}$ & 12.5 & 2.6 \\
\hline
\end{tabular}


Table 8: Pearson's correlation coefficient (r) matrix for comminuting I1 and I2 pellets.

\begin{tabular}{l|llllllllll}
\hline & $\dot{\mathrm{m}}_{\text {Pellet }}$ & $\dot{\mathrm{m}}_{\text {Air }}$ & HGP & $\mathrm{n}$ & $\mathrm{d}^{*}$ & $\mathrm{D} 90$ & $\mathrm{~K}_{\mathrm{R}}$ & $\mathrm{P}$ & SGEC & $\Delta \mathrm{p}$ \\
\hline$\dot{\mathrm{m}}_{\text {Pellet }}$ & 1.00 & & & & & & & & & \\
$\dot{\mathrm{m}}_{\text {Air }}$ & $0.90^{\mathrm{a}}$ & 1.00 & & & & & & & & \\
$\mathrm{HGP}$ & $1.00^{\mathrm{c}}$ & $0.89^{\mathrm{a}}$ & 1.00 & & & & & & & \\
$\mathrm{n}$ & 0.79 & 0.59 & $0.81^{\mathrm{a}}$ & 1.00 & & & & & & \\
$\mathrm{~d}^{*}$ & 0.78 & 0.44 & 0.79 & 0.81 & 1.00 & & & & & \\
$\mathrm{D} 90$ & 0.74 & 0.40 & 0.76 & 0.80 & $1.00^{\mathrm{c}}$ & 1.00 & & & & \\
$\mathrm{~K}_{\mathrm{R}}$ & $0.92^{\mathrm{b}}$ & 0.72 & $0.93^{\mathrm{b}}$ & 0.73 & $0.89^{\mathrm{a}}$ & $0.87^{\mathrm{a}}$ & 1.00 & & & \\
$\mathrm{P}$ & $0.88^{\mathrm{a}}$ & 0.76 & $0.89^{\mathrm{a}}$ & 0.62 & 0.71 & 0.66 & $0.93^{\mathrm{b}}$ & 1.00 & & \\
$\mathrm{SGEC}$ & $-0.94^{\mathrm{b}}$ & $-0.87^{\mathrm{a}}$ & $-0.93^{\mathrm{b}}$ & -0.65 & -0.70 & -0.67 & $-0.81^{\mathrm{a}}$ & -0.73 & 1.00 & \\
$\Delta \mathrm{p}$ & 0.80 & 0.49 & 0.81 & $0.85^{\mathrm{a}}$ & $0.89^{\mathrm{a}}$ & $0.87^{\mathrm{a}}$ & $0.81^{\mathrm{a}}$ & 0.74 & -0.71 & 1.00 \\
\hline${ }^{\mathrm{a}} \mathrm{p}<0.05,{ }^{\mathrm{b}} \mathrm{p}<0.01$ and $^{\mathrm{c}} \mathrm{p}<0.001$. & & & & & & &
\end{tabular}




\section{Fig. 1:}

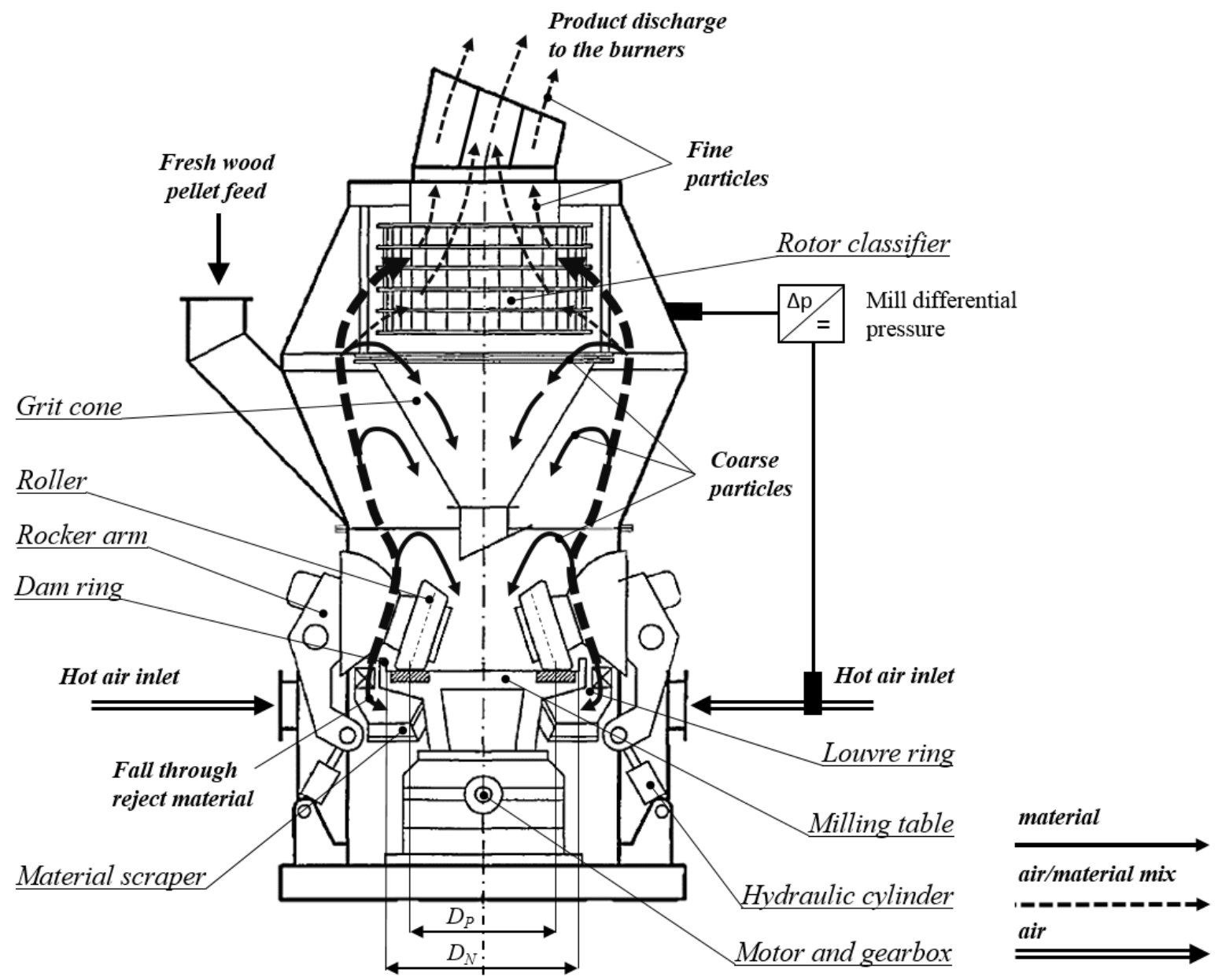


Fig. 2:

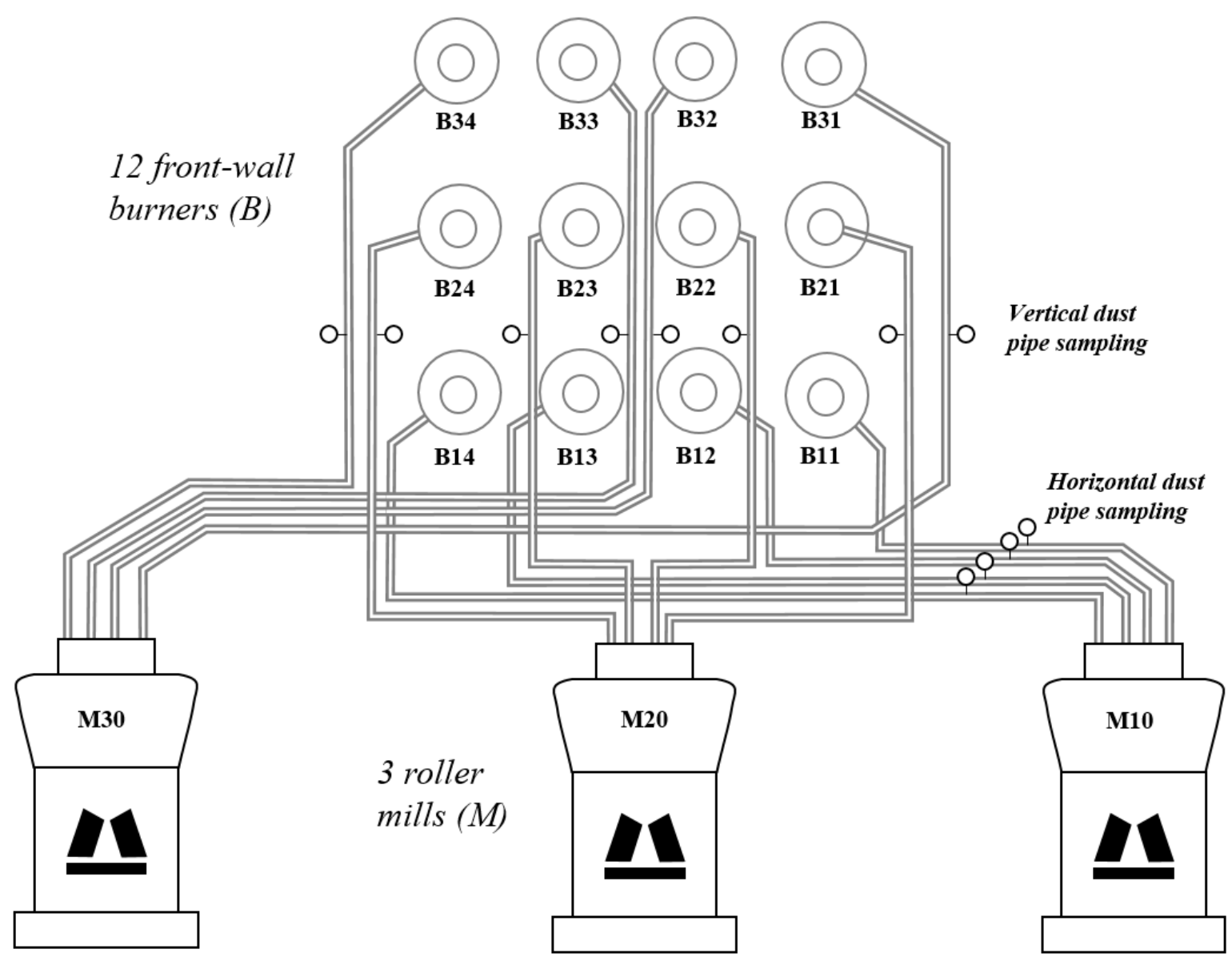




\section{Fig. 3:}

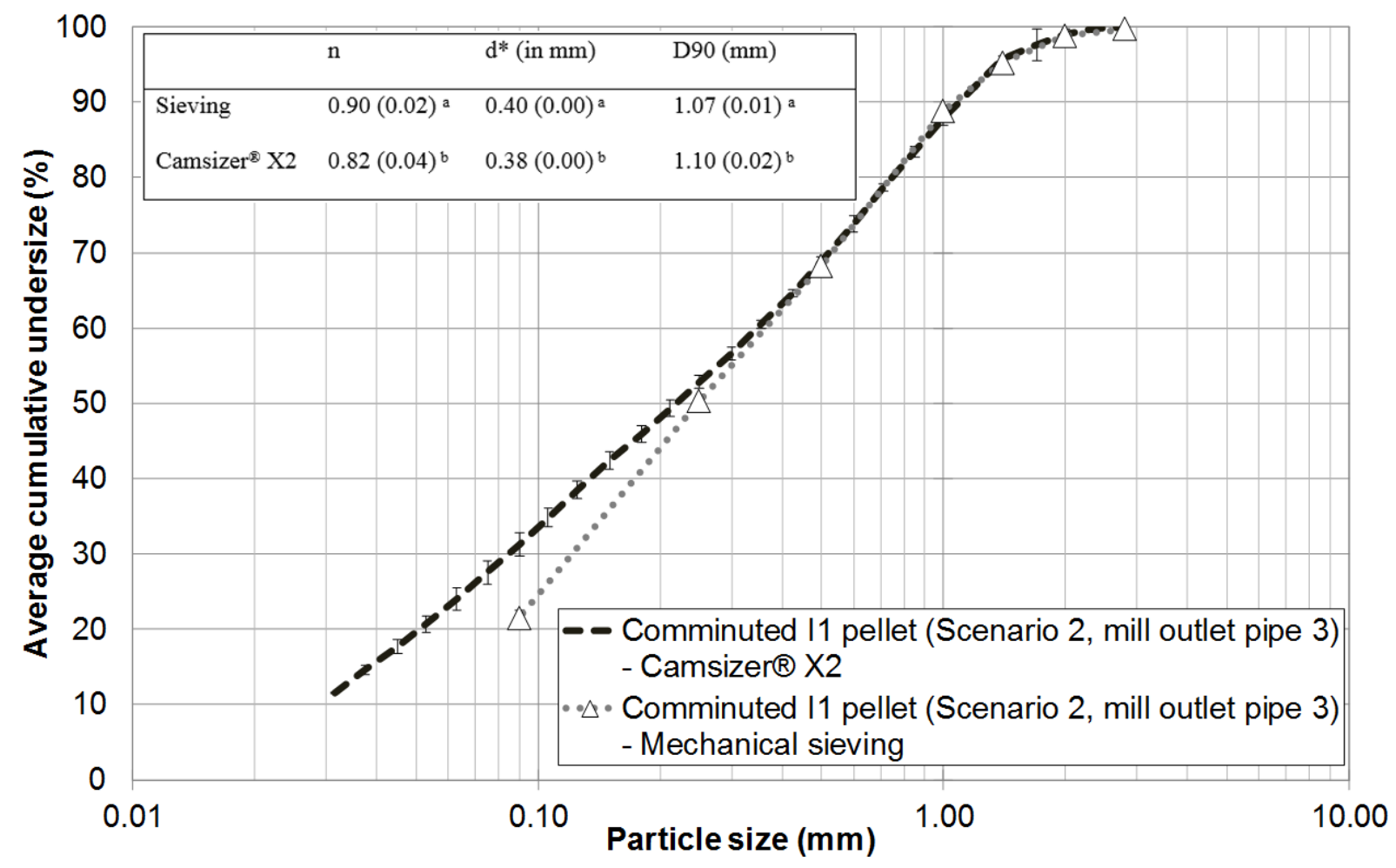




\section{Fig. 4:}

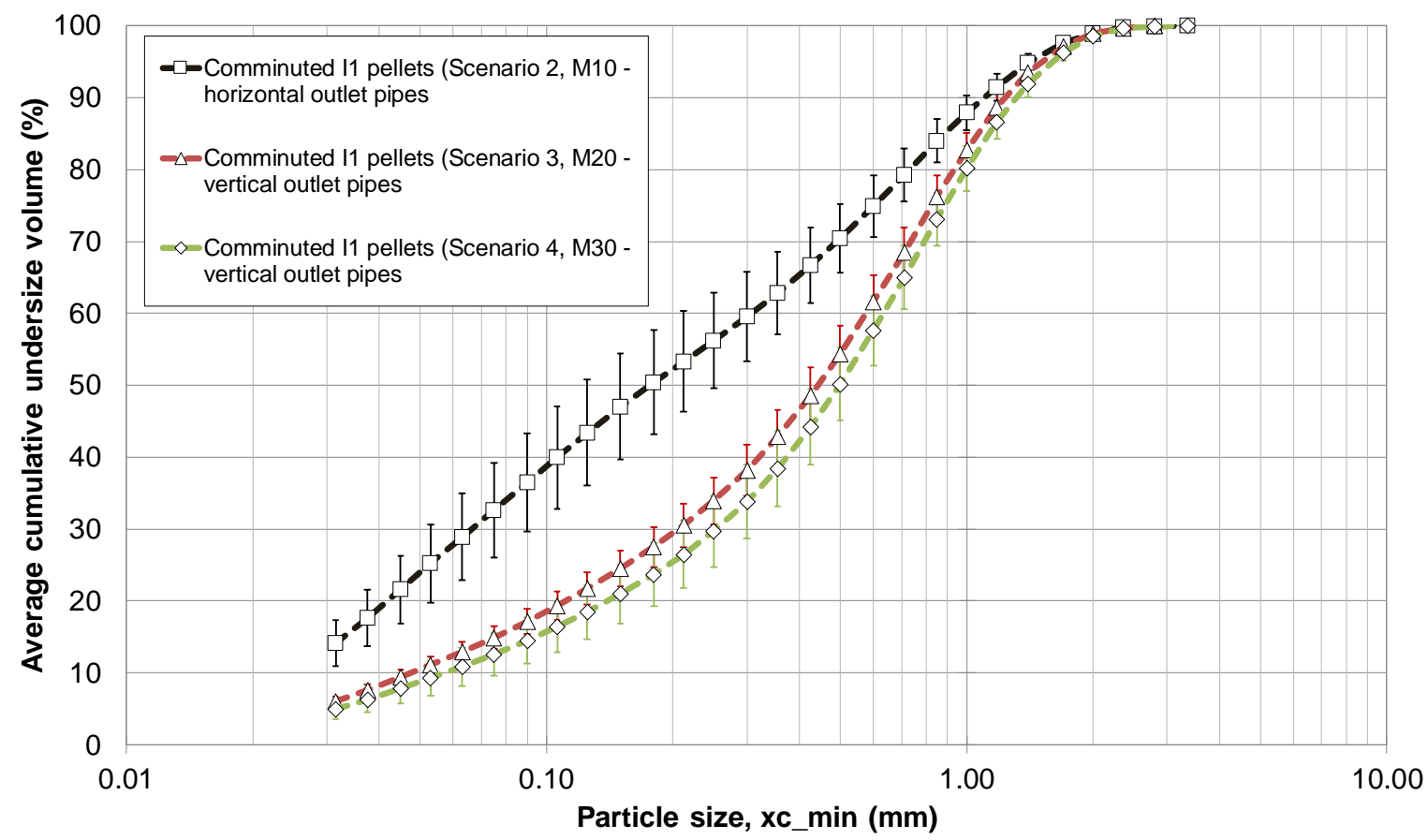

Masche et al. / Wood Pellet Milling Tests in a Suspension-Fired Power Plant / 50 


\section{Fig. 5:}

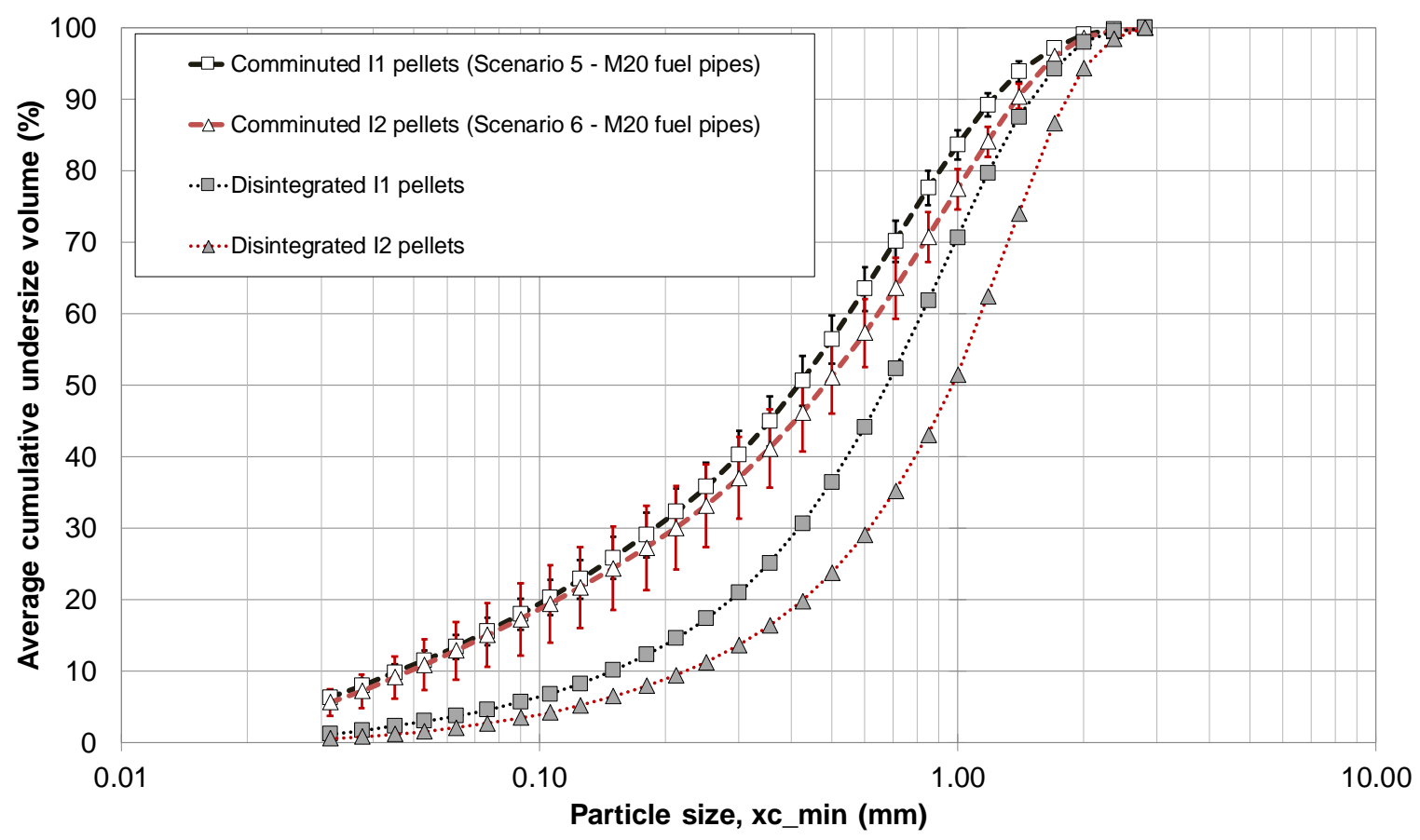

Masche et al. / Wood Pellet Milling Tests in a Suspension-Fired Power Plant / 51 


\section{Fig. 6:}
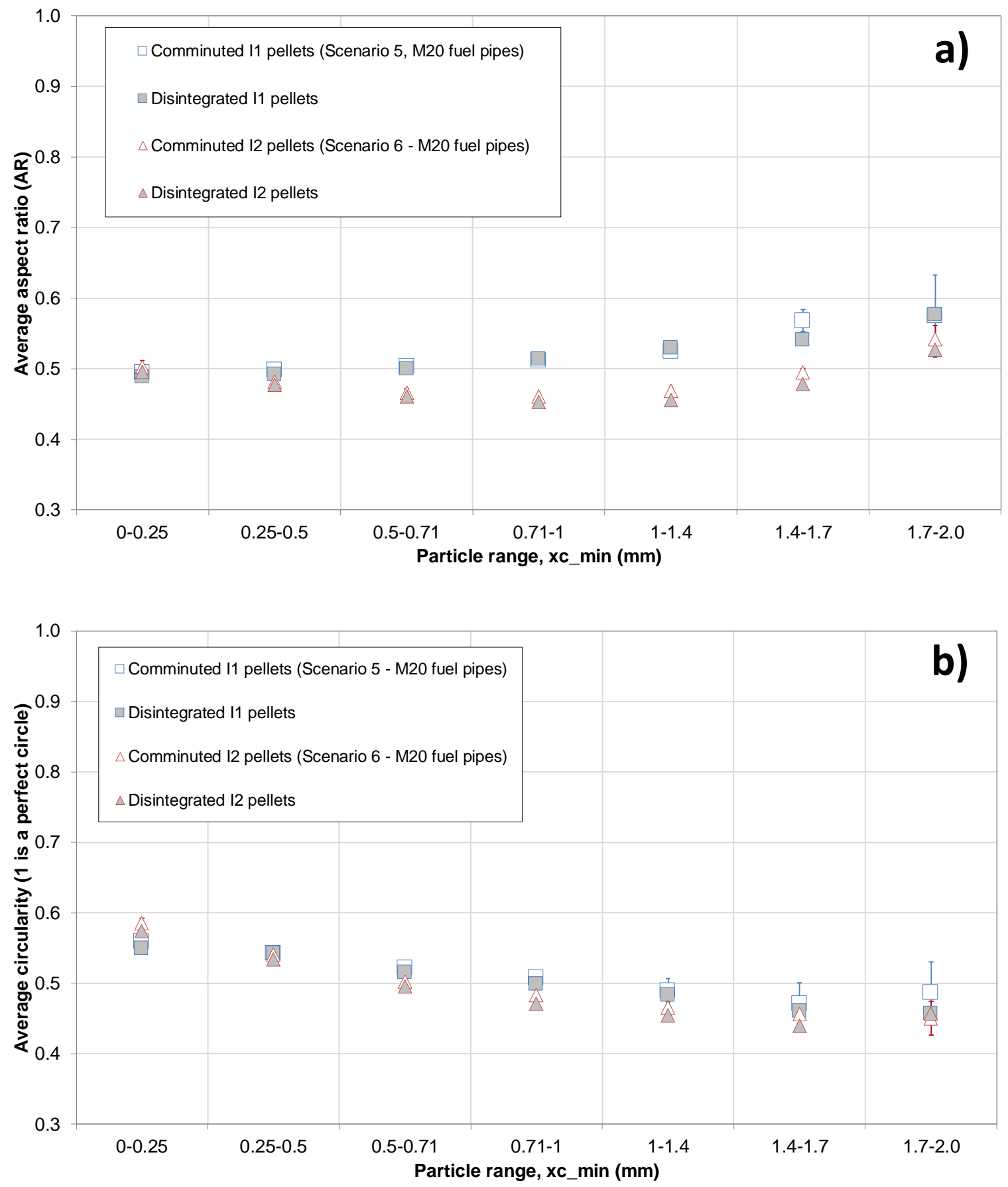

Masche et al. / Wood Pellet Milling Tests in a Suspension-Fired Power Plant / 52 


\section{Fig. 7:}

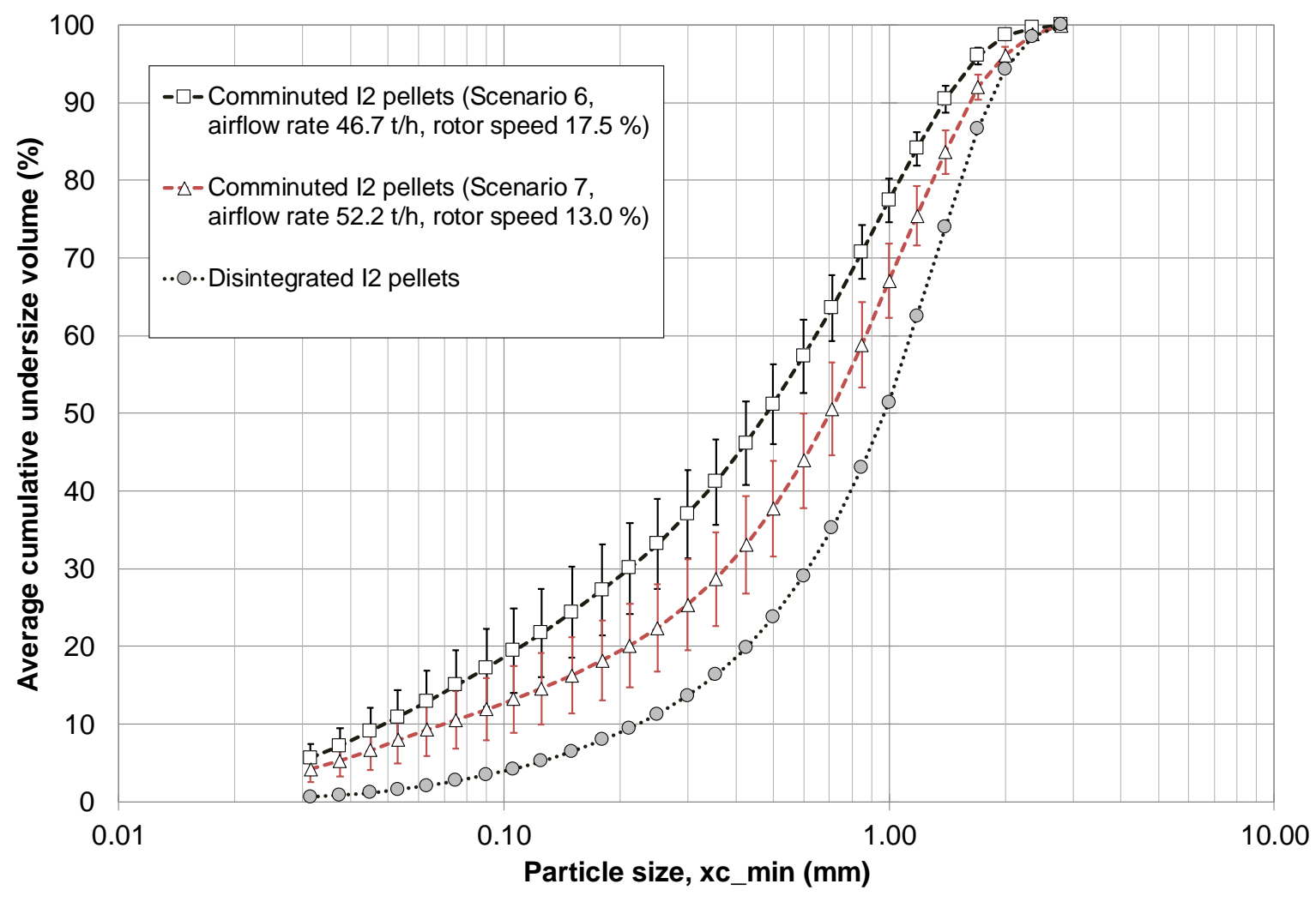

Masche et al. / Wood Pellet Milling Tests in a Suspension-Fired Power Plant / 53 


\section{Fig. 8:}
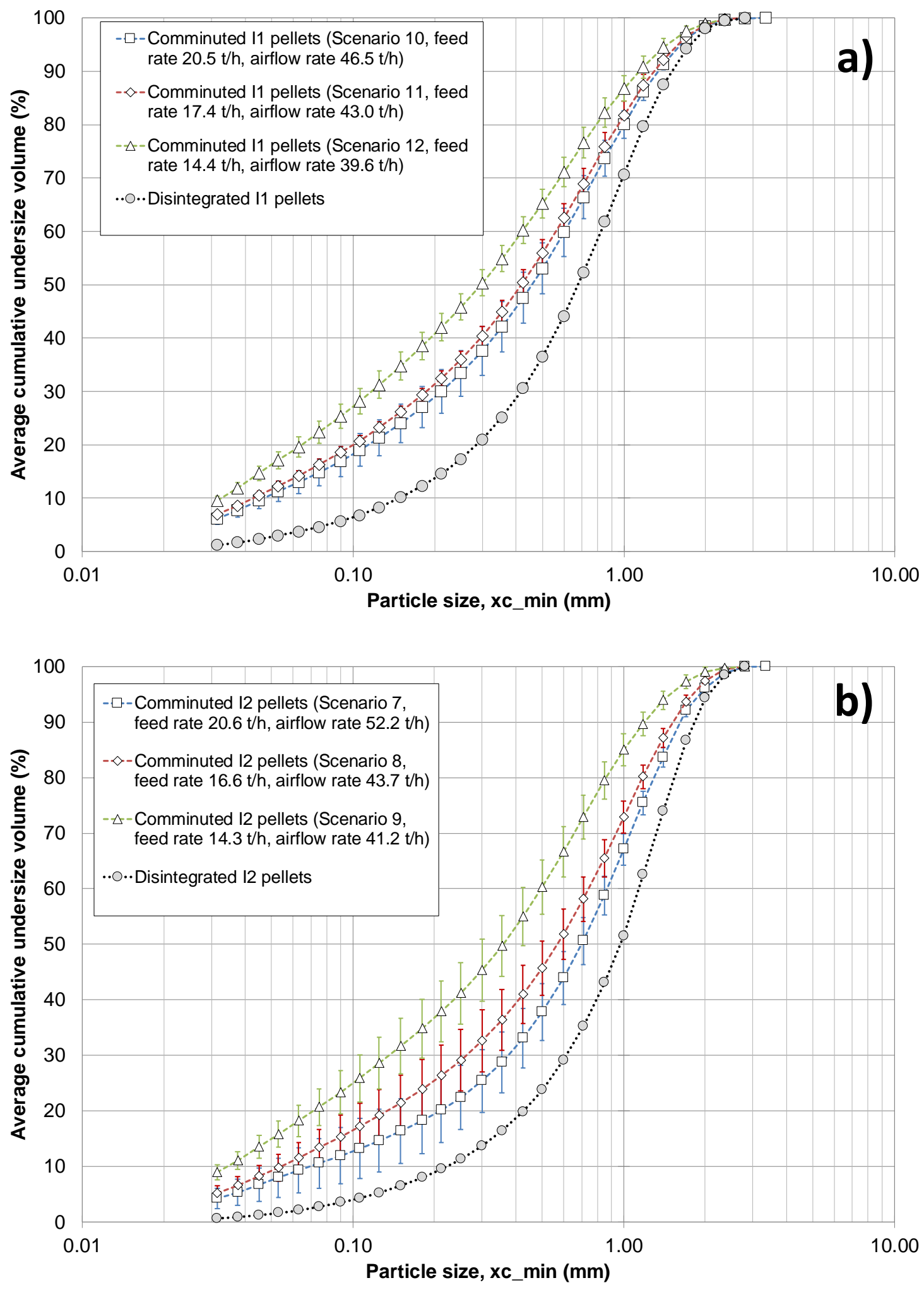

Masche et al. / Wood Pellet Milling Tests in a Suspension-Fired Power Plant / 54 


\section{Fig. 9:}

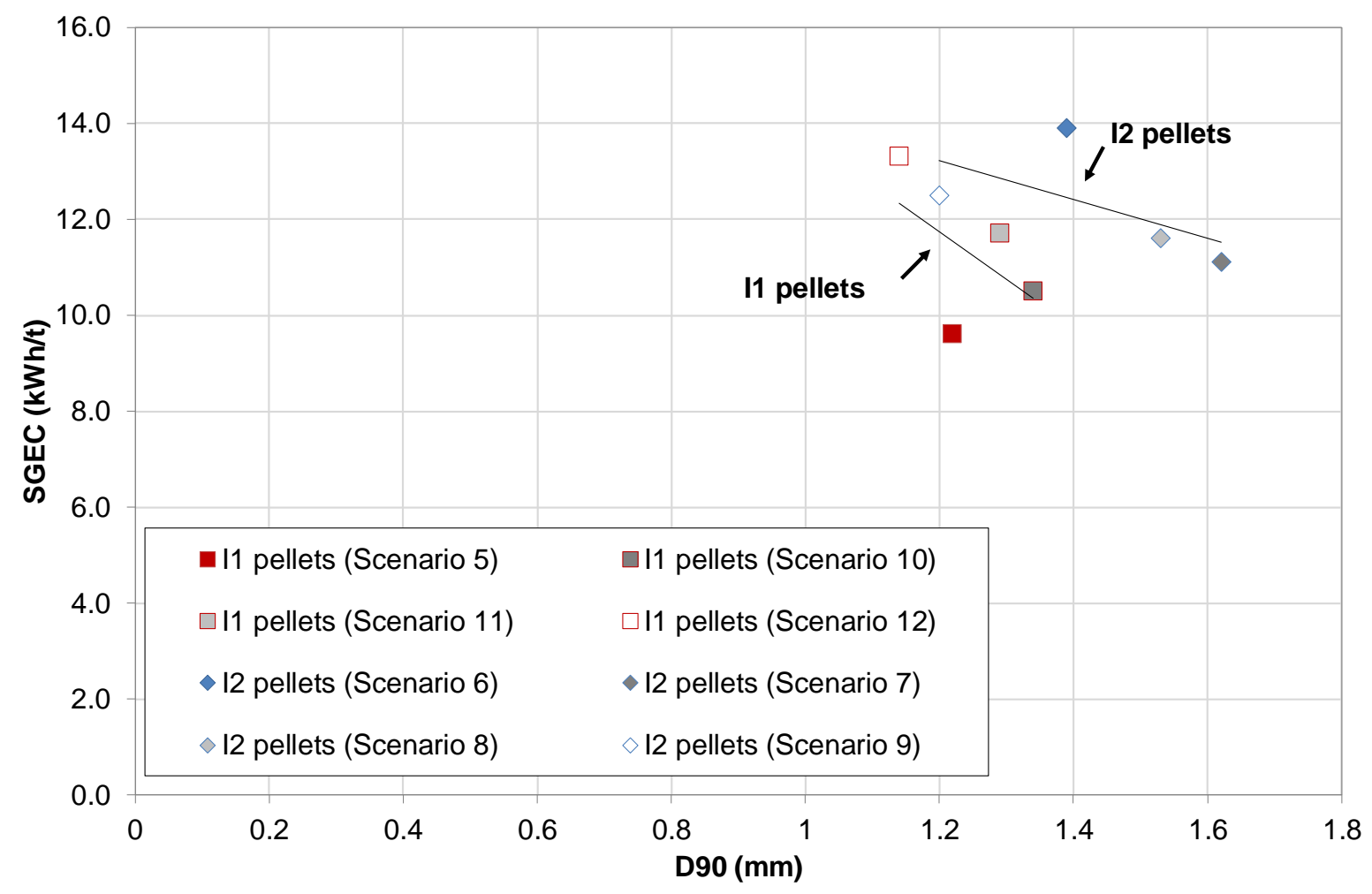

